Research

\title{
Impairment of alternative splice sites defining a novel gammaretroviral exon within gag modifies the oncogenic properties of Akv murine leukemia virus
}

\author{
Annette Balle Sørensen ${ }^{1,6}$, Anders H Lund ${ }^{1,7}$, Sandra Kunder ${ }^{2}$, \\ Leticia Quintanilla-Martinez ${ }^{2}$, Jörg Schmidt ${ }^{3}$, Bruce Wang ${ }^{4}$, Matthias Wabl ${ }^{5}$ \\ and Finn Skou Pedersen*1
}

Address: ${ }^{1}$ Department of Molecular Biology, University of Aarhus, Denmark, ${ }^{2}$ Institute of Pathology, GSF-National Research Center for Environment and Health, Neuherberg, Germany, ${ }^{3}$ Department of Comparative Medicine GSF-National Research Center for Environment and Health, Neuherberg, Germany, ${ }^{4}$ Picobella, Burlingame, CA, USA, ${ }^{5}$ Department of Microbiology and Immunology, University of California-San Francisco, San Francisco, CA, USA, ${ }^{6}$ The State and University Library, Universitetsparken, DK-8000 Aarhus C, Denmark and ${ }^{7}$ Biotech Research and Innovation Centre (BRIC), University of Copenhagen, Ole Maaløes Vej 5, DK-2200 Copenhagen N, Denmark

Email: Annette Balle Sørensen - abs@statsbiblioteket.dk; Anders H Lund - anders.lund@bric.dk; Sandra Kunder - sandra.kunder@gsf.de; Leticia Quintanilla-Martinez - quintanilla-fend@gsf.de; Jörg Schmidt - joerg.schmidt@gsf.de; Bruce Wang - bruce@picobella.com; Matthias Wabl - mutator@itsa.ucsf.edu; Finn Skou Pedersen* - fsp@mb.au.dk

* Corresponding author

Published: 6 July 2007

Retrovirology 2007, 4:46 doi:10.1 186/1742-4690-4-46
Received: 7 March 2007

Accepted: 6 July 2007

This article is available from: http://www.retrovirology.com/content/4/1/46

(c) 2007 Sørensen et al; licensee BioMed Central Ltd.

This is an Open Access article distributed under the terms of the Creative Commons Attribution License (http://creativecommons.org/licenses/by/2.0), which permits unrestricted use, distribution, and reproduction in any medium, provided the original work is properly cited.

\begin{abstract}
Background: Mutations of an alternative splice donor site located within the gag region has previously been shown to broaden the pathogenic potential of the T-lymphomagenic gammaretrovirus Moloney murine leukemia virus, while the equivalent mutations in the erythroleukemia inducing Friend murine leukemia virus seem to have no influence on the disease-inducing potential of this virus. In the present study we investigate the splice pattern as well as the possible effects of mutating the alternative splice sites on the oncogenic properties of the B-lymphomagenic Akv murine leukemia virus.
\end{abstract}

Results: By exon-trapping procedures we have identified a novel gammaretroviral exon, resulting from usage of alternative splice acceptor (SA') and splice donor (SD') sites located in the capsid region of gag of the B-cell lymphomagenic Akv murine leukemia virus. To analyze possible effects in vivo of this novel exon, three different alternative splice site mutant viruses, mutated in either the SA', in the SD', or in both sites, respectively, were constructed and injected into newborn inbred NMRI mice. Most of the infected mice (about 90\%) developed hematopoietic neoplasms within 250 days, and histological examination of the tumors showed that the introduced synonymous gag mutations have a significant influence on the phenotype of the induced tumors, changing the distribution of the different types as well as generating tumors of additional specificities such as de novo diffuse large $B$ cell lymphoma (DLBCL) and histiocytic sarcoma. Interestingly, a broader spectrum of diagnoses was made from the two single splice-site mutants than from as well the wild-type as the double splice-site mutant. Both single- and doublespliced transcripts are produced in vivo using the SA' and/or the SD' sites, but the mechanisms underlying the observed effects on oncogenesis remain to be clarified. Likewise, analyses of provirus integration sites in tumor tissues, which identified I I I novel RISs (retroviral integration sites) and 35 novel CISs (common integration sites), did not clearly point to specific target genes or pathways to be associated with specific tumor diagnoses or individual viral mutants.

Conclusion: We present here the first example of a doubly spliced transcript within the group of gammaretroviruses, and we show that mutation of the alternative splice sites that define this novel RNA product change the oncogenic potential of Akv murine leukemia virus. 


\section{Background}

Many murine leukemia viruses (MLVs) belonging to the genus gammaretroviruses induce cancer when injected into susceptible newborn mice $[1,2]$. These simple retroviruses do not themselves harbor transduced oncogenes, and their ability to cause cancer relies on the host cellular genes that are transcriptionally activated or otherwise mutated as a result of the integrated provirus [3-6].

Regarding the virus itself, it is well documented that the LTR region plays a crucial role for both the strength and cell type specificity of disease induction $[7,8]$. Within the LTR the specificity has been located mainly to the enhancer region in $\mathrm{U} 3$, and further narrowed down to the sequences defining different transcription factor binding sites [9-12]. In spite of this predominant role of the LTR in MLV pathogenesis, also sequences outside this region have been shown to be important for the ability and potency of a particular virus to induce cancer. Infection is mediated by interaction between the viral envelope protein (Env) and a specific host cell receptor, and for the ecotropic MLVs such as Moloney, Akv, and SL3-3, this receptor has been identified as the mouse cationic amino acid transporter 1 (mCAT1) [13,14]. A significant role of $e n v$ in MLV pathogenesis is the involvement in the generation of recombinant polytropic viruses that takes place during T-cell lymphoma development. These MCF (mink cell focus-forming) viruses have the ability to superinfect cells, an aspect which is thought to contribute to tumor formation $[15,16]$. In addition to the env gene, and perhaps somewhat surprisingly, the viral gag gene sequences have also proven to play a role in MLV pathogenesis. Thus, Audit et al. (1999) [17] showed that the introduction of only three synonymous nucleotide mutations in the capsid-coding gene of Moloney MLV (Mo-MLV) changed the oncogenic properties of this virus. The mutations were located at an alternative splice donor site (SD'), which together with the canonical env splice acceptor site was shown to produce a subgenomic transcript of $4.4 \mathrm{~kb}$ [18]. The equivalent transcript, produced by Friend MLV, was subsequently shown to be packaged into virions, reversely transcribed and integrated in the host genome by normal viral mechanisms [19]. While wild-type Mo-MLV induces T-cell lymphomas in $100 \%$ of the inoculated mice, the SD' mutant virus exhibited a much broader specificity, thus inducing - besides the expected T-cell tumors - erythroid or myelomonocytic leukemias. In contrast, the corresponding mutations in a Friend MLV background did not seem to influence the pathogenic potential of this virus at all. Both wild-type and mutant Friend MLVs induced exclusively the characteristic erythroleukemia [17]. So it seems that the importance for the diseaseinducing potential of the SD' site, although conserved among many species, is strongly dependent on the virus type.
The SD' site has also been found to be used for production of the oncogenic gag-myb fusion RNAs in promonocytic leukemias induced by Mo-MLV in pristane-treated BALB/ c mice [20]. When the SD' site was mutated in this model, the overall disease incidence was not affected; however the proportion of myeloid leukemia decreased significantly, while the proportion of lymphoid leukemia increased. Moreover, no 5 ' insertional activation of c-myb (using alternative splice donor sites) could be found, thereby signifying a specific requirement of the SD' site for this mechanism [21].

Here we report of the identification of an alternative splice acceptor site, SA', located in the capsid region of gag, which together with the gag splice donor site, SD' (corresponding to the one reported for Moloney and Friend MLV), or together with a second alternative gag splice donor site, $\mathrm{SD}^{*}$, defines a novel exon within the genus gammaretroviruses. We show that RNA splicing by use of the alternative splice sites does indeed take place in tumor tissue, and that both double- and single-spliced transcripts are produced. When mutating the $\mathrm{SD}^{\prime}$, the $\mathrm{SA}^{\prime}$, or both sites simultaneously, the splicing pattern is affected in a predictable way. Moreover, we demonstrate that the $\mathrm{SA}^{\prime}$ and SD' mutations alter the oncogenic specificity of the Akv MLV, displayed by a change in the distribution of the diagnoses of the resulting tumors as well as by an induction of tumors of altered specificity such as histiocytic sarcoma and de novo diffuse large B cell lymphoma (DLBCL).

\section{Results \\ Identification of a novel exon residing within the gag region of Akv MLV}

In order to identify potential alternative splice donor and splice acceptor sites in Akv MLV, exon-trapping was performed using the exon-trapping vector pSPL3 (see Materials and Methods). In short, an exon resulting from usage of the alternative splice acceptor (SA') and either one of two alternative splice donor (SD' or $\mathrm{SD}^{*}$ ) sites located in the capsid region of gag (Fig. 1), was isolated and verified by RT-PCR analyses of RNA isolated from Akv MLV infected cells (data not shown). The size of the exon is 235 bp or $180 \mathrm{bp}$, depending on the splice donor site used.

\section{Mutations of the alternative splice sites affect the specificity of the induced tumors}

To analyze a possible effect in vivo of the novel exon, defined by $\mathrm{SA}^{\prime}$ and $\mathrm{SD}^{\prime}$, three different alternative splice site mutant viruses, Akv-CD, Akv-EH, and Akv-CDH, mutated in either the SA' or SD' site, or in both sites simultaneously, were constructed and injected into newborn mice of the inbred NMRI strain. Fig. 1 shows the precise locations of the synonymous mutations around the trapped exon. Without altering the coding potential of the 


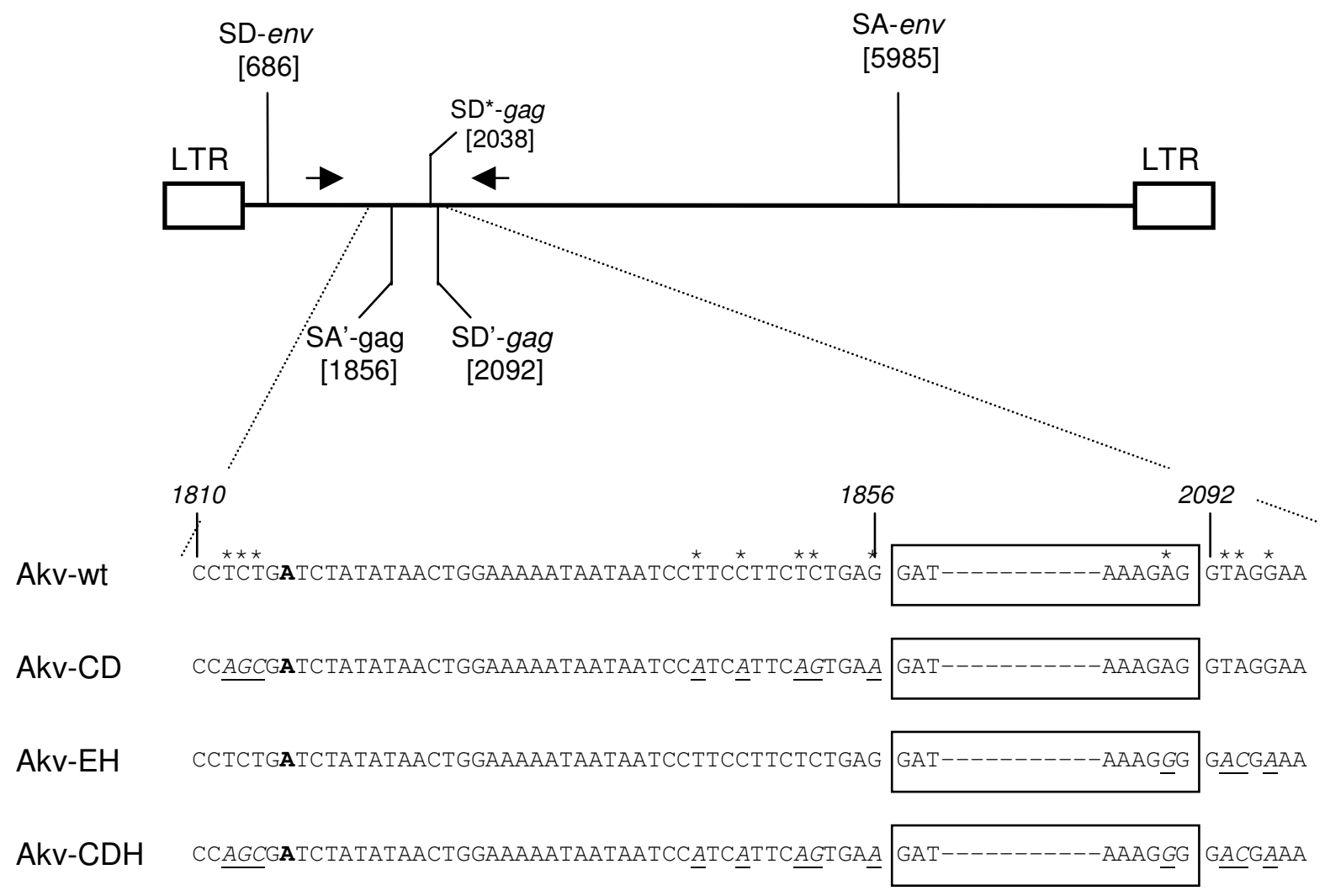

\section{Figure I}

Location of the trapped exon. Upper panel shows the structure of proviral Akv MLV DNA with the positions of the splice sites indicated (SD; splice donor, SA; splice acceptor). Arrows signify the PCR primers used to verify the stability of the introduced mutations. Lower panel shows the positions and types of the introduced mutations, marked by asterisks and underlined. The $\mathrm{SA}^{\prime} / \mathrm{SD}$-delineated exon is indicated by the box. The boldfaced $\mathrm{A}$ in the sequence indicates the presumed branch point.

capsid gene, the mutations affect the branch point site, the pyrimidine region, the conserved splice junction AG and GT dinucleotides, and the fairly well-conserved exonal A at the SD' junction site. The positions of the three intron mutations at the SD' junction site are identical to those in Moloney and Friend MLV described by Audit et al. (1999) [17].

As can be seen from Fig. 2 and Table 1 the majority of the infected mice (about 90\%) developed tumors within 250 days with similar average latency periods of about 200 days for the four types of virus. Histological examination (examples shown in Fig. 3) and diagnosis according to the Bethesda classification [22] revealed that a large proportion (approx. 70\%) of the total numbers of tumors could be classified as either follicular B-cell lymphoma (FBL) (13\%), diffuse large B-cell lymphoma (DLBCL) progressed from FBL (33\%), or plasmacytoma (PCT) (25\%) (Table 2). However, the distribution was quite different within the different virus series; thus, almost one quarter of the Akv-wt induced tumors were diagnosed as FBL, while no tumor of the Akv-CD group $(\mathrm{p}<0.05)$ or one tumor each of the Akv-EH or Akv-CDH groups fell into this group. In contrast, within the DLBCL tumors progressed from FBL the frequencies are similar (ranging from $24 \%$ to $39 \%$ ) no matter if the causative virus contained mutated SA' and/or SD' sites or not. In the PCT group it appears that mutating the SA' site significantly impaired the ability of the virus to induce PCT $(\mathrm{p}<0.05)$. On the other hand, this effect was not statistically significant if the SD' site was mutated, and curiously if both sites were mutated, wild-type level for PCT induction was restored.

In line with this, the most dramatic effect in general was seen when only the SA' site was mutated as shown for Akv$\mathrm{CD}$; the tumor incidence of this mutant with respect to splenic marginal zone lymphoma (SMZL) increased from 


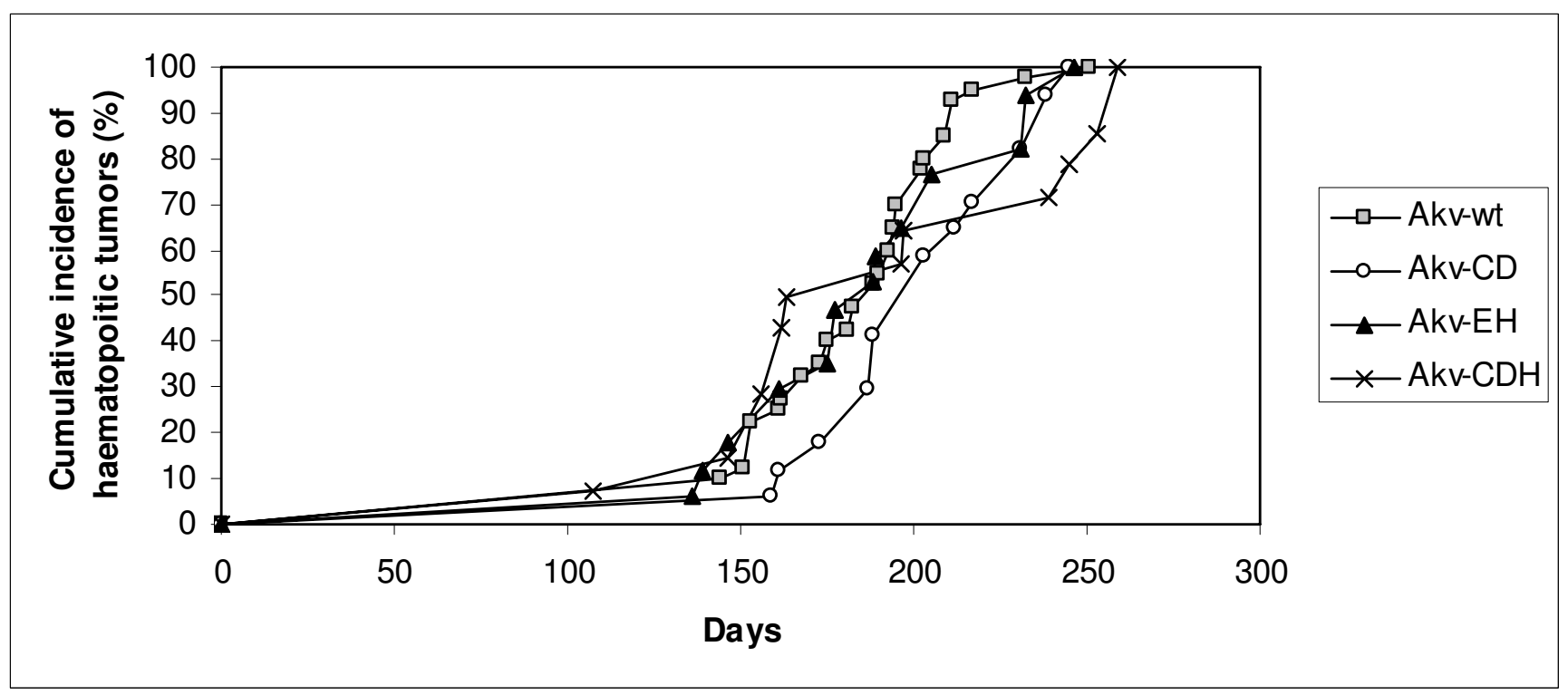

Figure 2

Pathogenicity of Akv and derived splice site mutants in inbred NMRI mice. Shown are the cumulative incidences of tumor development related to age of injected mice (in days).

$8 \%$ to $28 \%(\mathrm{p}<0.1)$ and decreased to $0 \%$ as shown for Akv-EH ( $<<0.05)$ and for Akv-CDH $(\mathrm{p}=0.5)$. Moreover, the Akv-CD mutant virus was the only one that displayed a capability for inducing histiocytic sarcoma, a tumor type which has not been observed in any of our previous studies using NMRI mice (inbred or random-bred) infected with Akv, SL3-3, or different derived mutants of these. So in brief, synonymous mutations at the SA' site of Akv MLV markedly altered the oncogenic potential of the virus by significantly impairing the ability to induce both FBL and PCT. Besides, while the development of SMZL was increased by Akv-CD, it was abolished in Akv-EH and Akv$\mathrm{CDH}$, and most notably, a novel potential for inducing histiocytic sarcoma was established.

The most pronounced effect of mutating the SD' site (Akv$\mathrm{EH})$ is the frequent occurrence (35\%) of diffuse tumors, which according to the Bethesda classification represent DLBCL centroblastic (more than 50\% of the infiltrating population is centroblasts). These tumors, where progression is not from either a follicular or a marginal lym- phoma, are comparable to the de novo lymphomas in humans, and to emphasize this association we have used the term de novo DLBCL (Table 2). Strikingly, de novo DLBCLs were never observed among the wild-type induced tumors or among the other mutant induced tumors ( $\mathrm{p}<$ 0.05). The finding of such tumors in mice is rare and could be exploited to understand the molecular changes in de novo DLBCL of mice, and eventually a useful mouse model of human de novo DLBCL might be generated from this set-up.

Quite unexpectedly, the effect of mutating the SA' and SD' sites simultaneously (Akv-CDH) was the less manifested one. FBL incidence dropped from $23 \%$ to $7 \%$; otherwise this mutant in our experimental setting displayed similar tumorigenic potential as the wild-type Akv MLV.

\section{Conservation of the introduced splice site mutations in the tumors}

To determine the stability of the introduced mutations, the regions containing the mutations were PCR amplified

Table I: Disease latency and frequency

\begin{tabular}{ccc}
\hline Virus & Average latency period (days) & Frequency of mice developing hematopoitic tumors \\
\hline Akv-wt & $184 \pm 26$ & $40 / 40$ \\
Akv-CD & $201 \pm 30$ & $17 / 19$ \\
Akv-EH & $184 \pm 34$ & $17 / 18$ \\
Akv-CDH & $190 \pm 46$ & $14 / 16$ \\
\hline
\end{tabular}



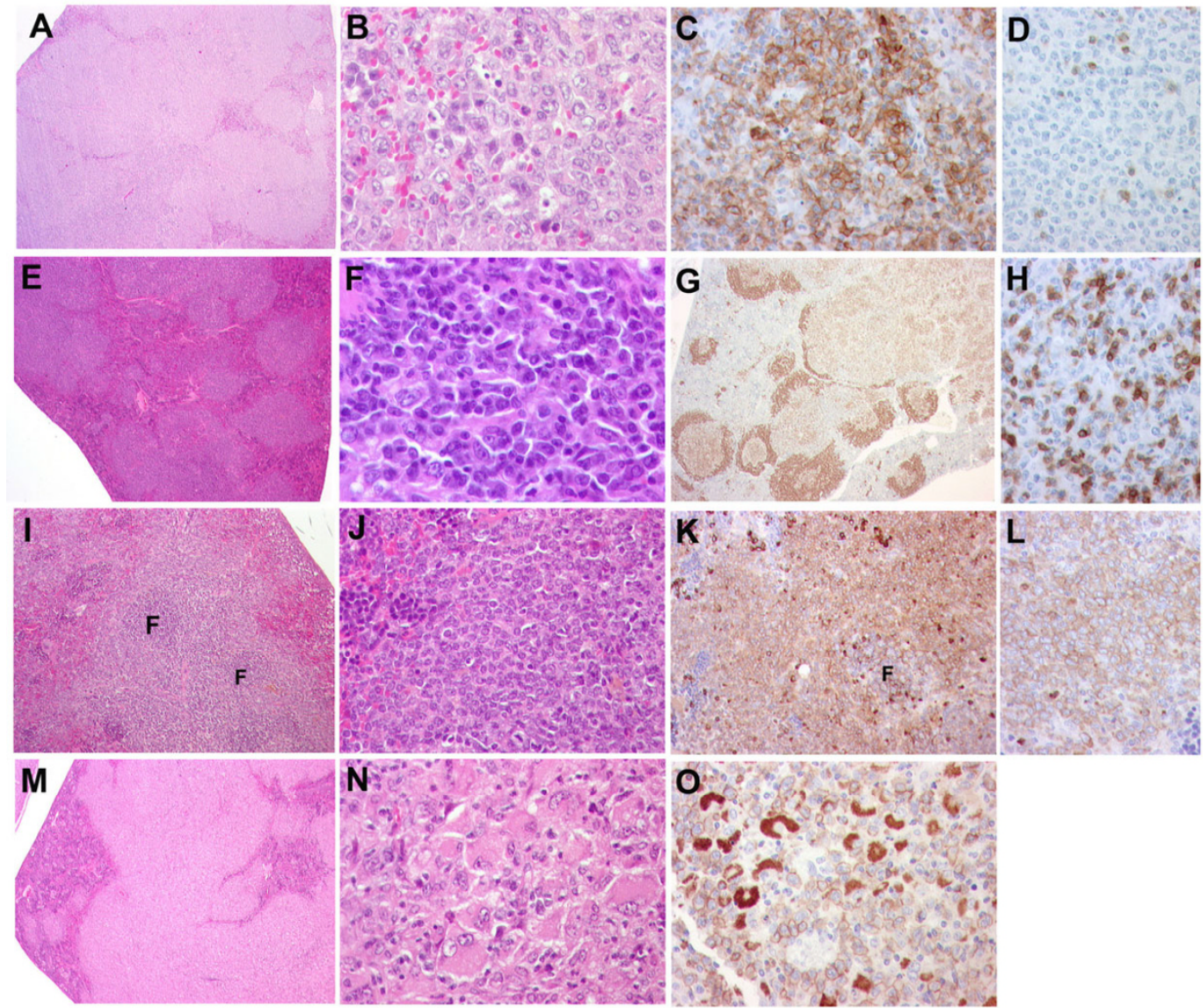

Figure 3

Histopathology of tumors induced by Akv and derived splice site mutants. Representative examples are shown. (A to D) de novo diffuse large B-cell lymphoma. (A) Low magnification of a spleen infiltrated by a vaguely nodular lymphoid neoplasia (H\&E staining). Magnification, $\times 25$. (B) Higher magnification demonstrates that the neoplasia is composed of a monotonous population of large cells with blastic chromatin, one to three nucleoli and abundant eosinophilic cytoplasm characteristic of centroblasts (H\&E staining). Magnification, $\times 640$. (C) Anti-B220 highlights the large neoplastic cells, which are strongly positive (immunohistochemistry). Magnification, $\times 400$. (D) Anti-CD3 shows that only few residual reactive T-cells are present (immunohistochemistry). Magnification, $\times 400$. (E to H) Follicular lymphoma. (E) Low magnification of a spleen infiltrated by a clear nodular lymphoid proliferation (H\&E staining). Magnification, $\times 25$ (F) Higher magnification shows a combination of large centroblasts intermingled with small- to medium-sized lymphocytes or centrocytes (H\&E staining). Magnification, $\times 640$. (G) AntiB220 highlights the expansion of the follicles, mainly of the germinal center lymphoid cells (light brown) (immunohistochemistry). Magnification, $\times 25$. $(\mathrm{H})$ Anti-CD3 reveals the presence of abundant reactive T-cells intermingled with the neoplastic Bcells (immunohistochemistry). Magnification, $\times 400$. (I to L) Marginal zone cell lymphoma. (I) Low magnification of a spleen infiltrated by a marginal zone lymphoma. Note that the follicles (F) are small and the cells surrounding these follicles expand and infiltrate the red pulp in a marginal zone pattern (H\&E staining). Magnification, $\times 100$. (J) Higher magnification showing that the neoplasia is composed of a monotonous population of small- to medium-sized cells with open fine chromatin, inconspicuous nucleoli and abundant light eosinophilic cytoplasm (H\&E staining). Magnification, $\times 400$. (K) Anti-CD79a reveals that the tumor cells in the marginal zone area are strongly positive, whereas the cells in the germinal centers (F) are weakly positive. The opposite staining pattern is seen with anti-B220 (data not shown) (immunohistochemistry). Magnification, $\times 200$. (L) Higher magnification with anti-CD79a shows a uniform membranous positivity of the tumor cells (immunohistochemistry). Magnification, $\times 400$. ( $M$ to $O)$ Histiocytic sarcoma. (M) Low magnification of a spleen diffusely infiltrated by a histiocytic sarcoma (H\&E staining). Magnification, $\times 25$. (N) Higher magnification shows the presence of large cells with abundant eosinophilic cytoplasm and bland nuclei characteristic of histiocytes (H\&E staining). Magnification, $\times 400$. (O) Anti-Mac 3 shows that all tumor cells are positive for this histiocytic marker, both in the cytoplasm and in the cell membrane (immunohistochemistry). Magnification, $\times 4$ Histopathological and immunohistological analyses of tumor tissues. 
Table 2: Frequency and latency of induced tumors

\begin{tabular}{|c|c|c|c|c|c|c|c|c|c|c|}
\hline Virus & FBL & $\begin{array}{c}\text { DLBCL } \\
\text { (progression } \\
\text { from FBL) }\end{array}$ & $\begin{array}{l}\text { De novo } \\
\text { DLBCL\# }\end{array}$ & PCT & SMZL & $\begin{array}{c}\text { DLBCL } \\
\text { (progression } \\
\text { from SMZL) }\end{array}$ & SBL & PTLL & STL & $\begin{array}{l}\text { Histiocytic } \\
\text { sarcoma }\end{array}$ \\
\hline Akv-wt & $9 / 40(23 \%)$ & $13 / 40(33 \%)$ & $0 / 40(0 \%)$ & I3/40 (33\%) & $3 / 40(8 \%)$ & $0 / 40(0 \%)$ & $2 / 40(5 \%)$ & $0 / 40(0 \%)$ & $0 / 40(0 \%)$ & $0 / 40(0 \%)$ \\
\hline Akv-CD* & $0 / 18(0 \%)$ & $7 / 18$ (39\%) & $0 / 18(0 \%)$ & $1 / 18(6 \%)$ & $5 / 18(28 \%)$ & $1 / 18(6 \%)$ & $0 / 18(0 \%)$ & $0 / 18(0 \%)$ & $0 / 18(0 \%)$ & $4 / 18(22 \%)$ \\
\hline Akv-EH & $1 / 17(6 \%)$ & $4 / 17(24 \%)$ & $6 / 17(35 \%)$ & $3 / 17(18 \%)$ & $0 / 17(0 \%)$ & $1 / 17(6 \%)$ & $0 / 17(0 \%)$ & $0 / 17(0 \%)$ & $1 / 17(6 \%)$ & $0 / 17(0 \%)$ \\
\hline Akv-CDH & $1 / 14(7 \%)$ & $5 / 14(36 \%)$ & $0 / 14(0 \%)$ & $5 / 14(36 \%)$ & $0 / 14(0 \%)$ & $0 / 14(0 \%)$ & $0 / 14(0 \%)$ & I/I4 (7\%) & $0 / 14(0 \%)$ & $0 / 14(0 \%)$ \\
\hline Total & II/88 (13\%) & $29 / 88(33 \%)$ & $6 / 88(7 \%)$ & $22 / 88$ (25\%) & $8 / 88(9 \%)$ & $2 / 88(2 \%)$ & $2 / 88(2 \%)$ & I/88 (I\%) & I/88 (I\%) & $4 / 88(5 \%)$ \\
\hline Av. latency period (days) & $188 \pm 30$ & $198 \pm 31$ & $187 \pm 43$ & $180 \pm 27$ & $207 \pm 20$ & $174 \pm 18$ & $153 \pm 12$ & 107 & 146 & $211 \pm 36$ \\
\hline
\end{tabular}

Abbreviations: FBL, follicular B cell lymphoma; DLBCL, diffuse large B cell lymphoma; PCT, plasmacytoma; SMZL, splenic marginal zone lymphoma; $\mathrm{SBL}$, small B cell lymphoma; PTLL, precursor T cell lymphoblastic lymphoma; STL, small T-cell lymphoma.

\# De novo DLBCL refers to Bethesda classification "DLBCL centroblastic"; however, to stress the parallel to human de novo lymphomas we use this term.

*In this group one of the 17 mice that developed tumors had two tumors, hence a total number of 18 tumors.

from genomic DNA prepared from the induced tumors, using the primers depicted in Fig. 1. The sequences of the amplified fragments confirmed in all cases the integrity of the introduced mutations (data not shown).

\section{Both single- and double-spliced transcripts are generated in vivo}

The observed effect of the mutated splice sites on the oncogenic properties advocates that RNA splicing by means of the alternative SA' and SD' sites does indeed take place in vivo. To clarify and confirm the identity of the produced transcripts, the splice pattern in tumor tissues (and for comparison in NIH 3 T3 cells infected with the same four viruses) was analyzed. RNA from the individual endstage tumors (or from virally infected cells) was isolated, and conventional RT-PCRs were performed with primers designed in such a way that it should be possible to identify all four potential splice products using 4 different primer sets as shown in Fig. 4A.

With a few exceptions, all tumors were analyzed, and sequences of the amplified RT-PCR products determined to validate the specificity of the fragments (data not shown). Representative results from each virus series are shown in Fig. 4B. In all cases, PCR products representing splice product A (the regular $e n v$ transcript; primer set \#4) was observed, which implies that damage of the alternative splice sites, SA' and SD', does not impair the production of the regular single-spliced env RNA. Concerning splice product D (primer set \#1) it was never amplified, neither from tumor tissues nor from cell culture studies, strongly indicating that this is not a bona fide transcript. The lack of detection of product $\mathrm{D}$ is unlikely to result from a technical PCR-problem since the two primers have been validated in other PCRs.

For the Akv wild-type induced tumors, RT-PCR products representing the double-spliced product B (primer set \#2), and fragments of expected size amplified by primer set \#3, indicative of splice product $\mathrm{B}$ or $\mathrm{C}$, were observed in all cases. As would be expected primer set \#2, which is dependent on an intact SA' site, did not result in any amplification products using RNA from Akv-CD or Akv$\mathrm{CDH}$ tumors. Surprisingly however, in five out of 14 analyzed Akv-EH tumor samples (represented by Akv-EH tumor no. 14 in Fig. 4B), a product slightly smaller than that of transcript version $B$ was amplified. The subsequent sequence analyses revealed that the alternative splice donor site SD* (depicted in Fig. 1) in these cases consistently had been used, resulting in the generation of a splice product equivalent in structure to product $\mathrm{B}$, however 54 nucleotides shorter. No correlation between tumor cell specificity and usage of the $\mathrm{SD}^{*}$ site could be observed, since the five tumor samples originated from FBL, DLBCL progressed from FBL, de novo DLBCL, and the single case of STL (small T-cell lymphoma). The presence of the same splice product from the $\mathrm{SD}^{*}$ site was verified by sequence analysis of RT-PCR products derived from tumors induced by the wild-type virus in some cases, although the product was consistently less prominent than product $\mathrm{B}$.

Transcript $\mathrm{C}$ corresponds to the single-spliced transcript of $4.4 \mathrm{~kb}$, which previously has been reported to be produced by both Friend and Moloney MLV using the SD' together with the canonical env SA' site $[18,19]$. Our RTPCR results confirm the existence of this single-spliced transcript, since products of the expected size were always amplified with primer set \#3 using RNA from Akv-CD tumors (Fig. 4B), whereas product B (primer set \#2) was never amplified in this material.

In summary, by means of the alternative splice sites that define the novel gag exon, both a single-spliced transcript $\mathrm{C}$ as well as a novel double-spliced transcript $\mathrm{B}$ is produced in vivo, and when these alternative splice sites are destroyed, the splicing pattern is changed concordantly. 
A

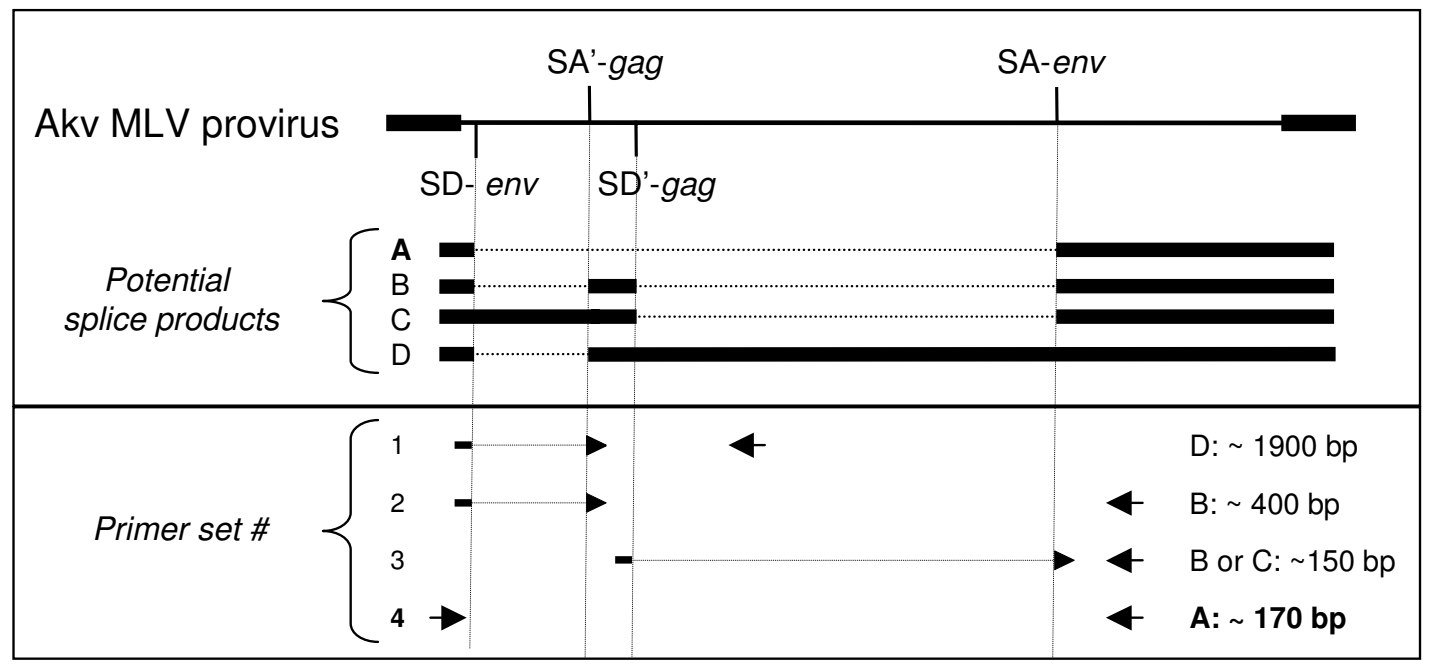

B

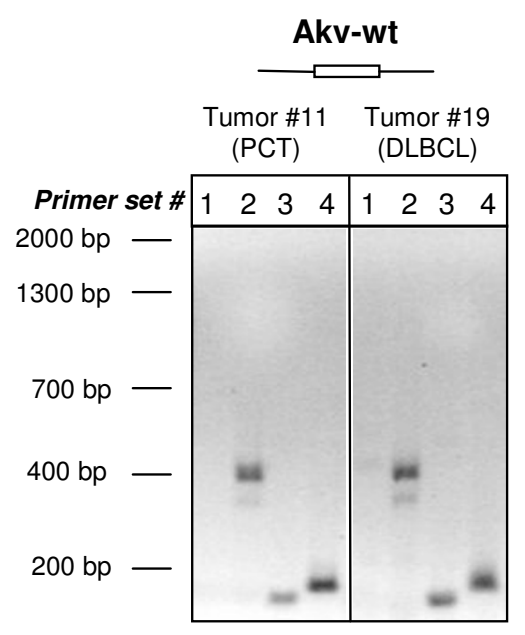

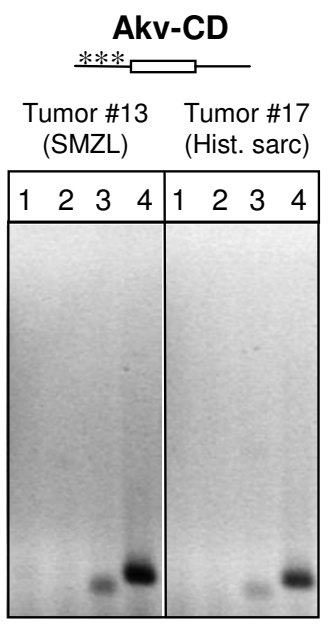

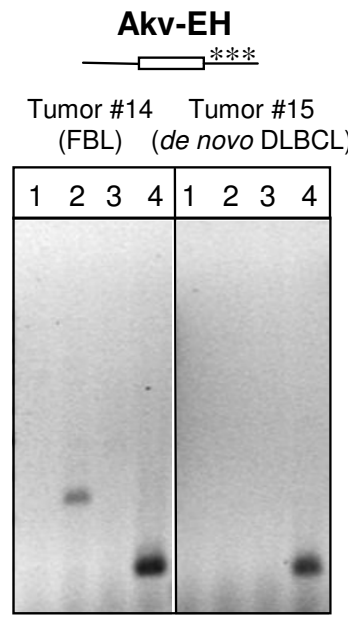

\section{Figure 4}

RT-PCR analyses of splice products generated in vivo. (A) The structures of the potential splice products $A$ to $D$ are illustrated at the top, with the positions and orientations of the PCR primers (see Materials and Methods) from the four primer sets depicted below. The predicted origins and sizes of the amplified fragments are given at the right. (B) Shown are examples from each series of amplified RT-PCR products visualized on ethidium bromide-stained agarose gels. The employed primer sets (\#I to \#4) are listed above the lanes. Size markers are indicated at the left.

The same RT-PCR analyses were performed for NIH 3T3 cells infected with the four viruses, which led to the same splice pattern (data not shown). In addition, Northern blot hybridizations with an ecotropic env-probe and with a probe covering the novel SA'-SD' defined exon in gag were performed with RNA isolated from these cells (Fig. 5 ). Besides the expected hybridization patterns of prominent bands of full-length (env and gag probe) and env mRNA (only env probe) sizes, a weaker band of a size corresponding to splice product $\mathrm{C}(4.4 \mathrm{~kb})$ was detected with both probes. No distinct band corresponding to spliced
RNA B was observed, suggesting a very low level of production and/or significant messenger instability.

\section{Provirus integration site analyses}

In order to identify a possible connection between specific retroviral integration sites (RIS) and specific diagnostic tumor types, provirus integration sites from the majority of the induced tumors were isolated and sequenced. We have then by subsequent homology searches of the mouse genome databases identified 240 unambiguous integration sites (Table 3). These integration site sequences rep- 

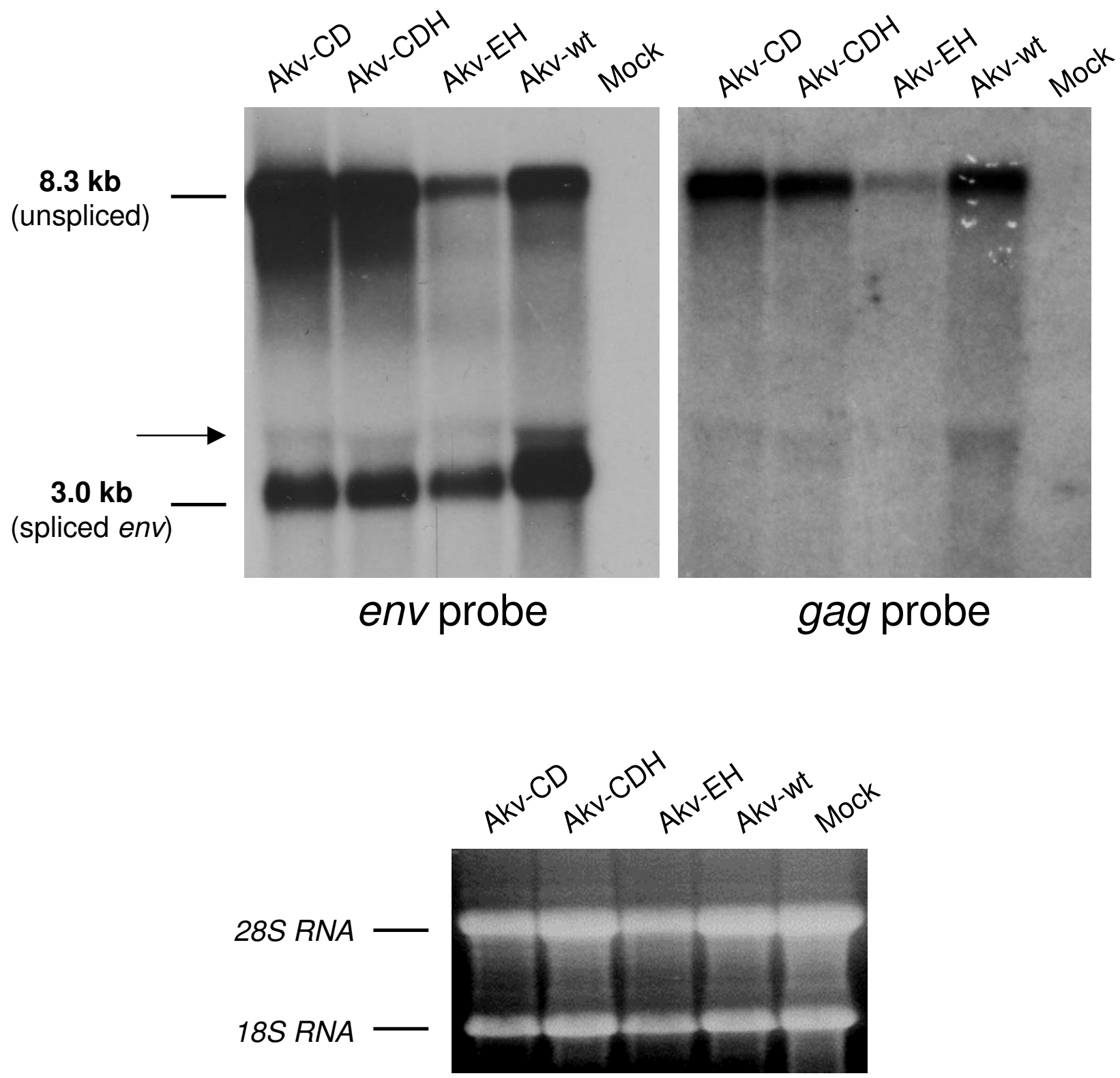

Figure 5

Northern blot hybridizations with an ecotropic specific env probe and a gag probe of RNA isolated from NIH 3 T3 cells chronically infected with the viruses listed above each lane. The sizes of the full-length transcript (unspliced) and the single-spliced env transcript are indicated at the left. The arrow indicates splice product $C$. For verification of integrity and concentration of the loaded RNA, the original ethidium bromide stained agarose gel exposing I8S and 28S rRNAs is shown below.

resent tumors from 30 out of 40 (104 sequences), 14 out of 19 (46 sequences), 14 out of 18 (51 sequences), and 11 out of 16 (39 sequences) mice infected by Akv-wt, Akv$\mathrm{CD}$, Akv-EH, and Akv-CDH, respectively. This corresponds to an average of 3.6 integrations per analyzed tumor. Based on the searches in the UCSC database [23], and the Mouse Retrovirus Tagged Cancer Gene Database, RTCGD [24,25], both version mm8, 111 novel RISs were identified. In an attempt to pick up candidate cancer genes that might be associated with specific tumor diagnoses, we looked for common integration sites (CISs), which would infer such genes $[25,26]$. Hence, we compared the 
Table 3: Positions of integrated proviruses in tumor DNA

\begin{tabular}{|c|c|c|c|c|c|c|c|c|}
\hline \# & Virus & Diagnosis & Chromosome & Position (mm8) & Gene/RefSeq $^{a}$ & No. of hits in RTCGD (mm8) & Novel RISsb & Novel CISsc \\
\hline 1 & Akv-EH & DLBCL (from FBL) & I & $2464 \mid 886$ & Lmbrdl & 0 & I & - \\
\hline 2 & Akv-EH & DLBCL (from FBL) & I & 36406157 & Cnnm4 & 0 & I & - \\
\hline 3 & Akv wt & DLBCL (from FBL) & I & 78743292 & Kcne4 & 0 & I & - \\
\hline 4 & Akv-EH & PCT & I & 82855932 & $\mathrm{Slc} 19 \mathrm{a} 3$ & 0 & I & - \\
\hline 5 & Akv wt & $\mathrm{FBL}$ & I & 93014894 & Rampl & 5 & - & - \\
\hline 6 & $A k v-C D$ & n.d. & I & 93022552 & & & & \\
\hline 7 & Akv-EH & Lymphoma, NOS & I & 120226476 & AK080782 & 0 & I & - \\
\hline 8 & Akv-CD & DLBCL (from FBL) & I & $13034 \mid 056$ & Cxcr4 & 3 & - & - \\
\hline 9 & Akv wt & РCT & I & $|358783| 6$ & Fmod/Btg2 & 8 & - & - \\
\hline 10 & Akv wt & DLBCL (from FBL) & I & $|35882| 83$ & & & & \\
\hline 11 & Akv-CD & Abscess & I & 139604557 & --- & 1 & - & 1 \\
\hline 12 & Akv wt & PCT & I & |44940508 & --- & 0 & I & - \\
\hline 13 & Akv wt & PCT & I & 163725782 & AK029097 & 0 & I & - \\
\hline 14 & Akv wt & FBL & I & 173476364 & Slamf7 & 0 & I & - \\
\hline 15 & Akv wt & PCT & I & 174350588 & Tagln2/AK006449 & 2 & - & - \\
\hline 16 & Akv wt & DLBCL (from FBL) & I & 182219328 & MGC68323/AK038867 & 2 & - & - \\
\hline 17 & Akv-CD & SMZL & 2 & 11542293 & $\| 2 \mathrm{ra}$ & 4 & - & - \\
\hline 18 & $\mathrm{Akv}-\mathrm{CDH}$ & DLBCL (from FBL) & 2 & 13133178 & Rsul & 0 & I & - \\
\hline 19 & Akv-CDH & PCT & 2 & 35270244 & Ggtal & 5 & - & - \\
\hline 20 & Akv wt & DLBCL (from FBL) & 2 & $4474 \mid 201$ & Gtdcl & 0 & I & - \\
\hline 21 & Akv wt & DLBCL (from FBL) & 2 & 46263959 & --- & 0 & I & - \\
\hline 22 & Akv wt & DLBCL (from FBL) & 2 & 71667822 & |tga6/Pdk| & 0 & I & - \\
\hline 23 & Akv wt & DLBCL (from FBL) & 2 & 90883313 & Slc39a 13/Sfpil & 6 & - & - \\
\hline 24 & Akv wt & SMZL & 2 & 90883476 & & & & \\
\hline 25 & Akv wt & PCT & 2 & 102668507 & $\mathrm{Cd} 44$ & 0 & I & - \\
\hline 26 & Akv wt & DLBCL (from FBL) & 2 & 102782324 & Pdhx & 0 & I & - \\
\hline 27 & Akv wt & $\mathrm{FBL}$ & 2 & 118352393 & Pak6 & 0 & i & - \\
\hline 28 & Akv wt & $\mathrm{FBL}$ & 2 & 119028536 & Spint I & 0 & i & - \\
\hline 29 & Akv-CDH & Lymphoma, NOS & 2 & 120301032 & Zfpl06 & I & - & I* \\
\hline 30 & $\mathrm{Akv}-\mathrm{CDH}$ & PTLL & 2 & $1288750 \mid 3$ & Slc20al & 0 & I & - \\
\hline 31 & Akv-CDH & Lymphoma, NOS & 2 & 129283153 & Ptpns I & I & - & I \\
\hline 32 & Akv-EH & PCT & 2 & $|3| 7|| 284$ & Rassf2 & 0 & I & - \\
\hline 33 & Akv-CDH & DLBCL (from FBL) & 2 & 158379688 & Ppplr16b & 4 & - & - \\
\hline 34 & Akv wt & SMZL & 2 & 164051325 & SIpi & 0 & I & - \\
\hline 35 & Akv wt & DLBCL (from FBL) & 2 & 169860192 & Zfp217 & 5 & - & - \\
\hline 36 & Akv wt & FBL & 3 & 22265638 & Tbllxrl & 0 & I & - \\
\hline 37 & Akv-CDH & PCT & 3 & 27464311 & Aadacll & 0 & I & - \\
\hline 38 & Akv-CDH & DLBCL (from FBL) & 3 & 30203814 & Evil & 5 & - & - \\
\hline 39 & Akv-CDH & PCT & 3 & 30203870 & & & & \\
\hline 40 & Akv-CDH & Lymphoma, NOS & 3 & 76043446 & Golph4 & 0 & I & - \\
\hline 41 & Akv-EH & DLBCL (from FBL) & 3 & 79339620 & --- & 0 & I & - \\
\hline 42 & Akv wt & $\mathrm{FBL}$ & 3 & 90334704 & Slc39al & 0 & I & - \\
\hline 43 & Akv-CD & DLBCL (from FBL) & 3 & 96900321 & $\mathrm{CdI} 60$ & 0 & I & - \\
\hline 44 & Akv wt & SMZL & 3 & $9803 \mid 475$ & LOC433632 & 13 & - & - \\
\hline
\end{tabular}


Table 3: Positions of integrated proviruses in tumor DNA (Continued)

\begin{tabular}{|c|c|c|c|c|c|}
\hline$\frac{5}{y}$ & 45 & Akv-EH & PCT & 3 & 98041399 \\
\hline$\frac{0}{1}$ & 46 & Akv-CD & SMZL & 3 & 98043109 \\
\hline$\stackrel{\Phi}{ \pm}$ & 47 & Akv-CDH & DLBCL (from FBL) & 3 & 98043150 \\
\hline Е & 48 & Akv wt & PCT & 3 & 98043377 \\
\hline$\stackrel{\bar{g}}{E}$ & 49 & Akv wt & DLBCL (from FBL) & 3 & 98043659 \\
\hline 气ั & 50 & $A k v-C D$ & SMZL & 3 & 98064421 \\
\hline$\stackrel{0}{\grave{x}}$ & 51 & $\mathrm{Akv}-\mathrm{CDH}$ & DLBCL (from FBL) & 3 & 98127957 \\
\hline 으 & 52 & Akv-EH & PCT & 3 & 108214198 \\
\hline 을 & 53 & Akv-CD & SMZL & 3 & | I582835| \\
\hline $\bar{\partial}$ & 54 & Akv wt & DLBCL (from FBL) & 3 & 131582947 \\
\hline$\frac{}{0}$ & 55 & Akv wt & SBL & 3 & 145870070 \\
\hline & 56 & Akv wt & DLBCL (from FBL) & 3 & 146091393 \\
\hline 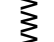 & 57 & Akv-EH & DLBCL (from FBL) & 3 & 157996860 \\
\hline & 58 & Akv wt & SBL & 4 & 8842182 \\
\hline & 59 & Akv-CDH & PCT & 4 & 11915327 \\
\hline & 60 & Akv-CD & DLBCL (from FBL) & 4 & 32560128 \\
\hline & 61 & Akv wt & FBL & 4 & 32611866 \\
\hline & 62 & Akv-CD & n.d. & 4 & 32619341 \\
\hline & 63 & Akv wt & PCT & 4 & 32702311 \\
\hline & 64 & Akv-CD & Histiocytic sarcoma & 4 & 44734542 \\
\hline & 65 & Akv wt & SMZL & 4 & 55369934 \\
\hline & 66 & Akv-CDH & Plasma cell prolif. & 4 & 57933461 \\
\hline & 67 & Akv-CD & DLBCL (from FBL) & 4 & 97386196 \\
\hline & 68 & Akv-EH & DLBCL (from FBL) & 4 & 132220004 \\
\hline & 69 & Akv wt & SMZL & 4 & 134699599 \\
\hline & 70 & Akv-CDH & РCT & 4 & 138050107 \\
\hline & 71 & Akv wt & FBL & 5 & 39921672 \\
\hline & 72 & Akv-CDH & Lymphoma, NOS & 5 & 65179064 \\
\hline & 73 & Akv-CD & Histiocytic sarcoma & 5 & 75074642 \\
\hline & 74 & Akv-CDH & PTLL & 5 & 107966364 \\
\hline & 75 & Akv-CDH & PCT & 5 & 121838640 \\
\hline & 76 & Akv-CDH & DLBCL (from FBL) & 5 & 141077075 \\
\hline & 77 & Akv wt & DLBCL (from FBL) & 6 & 29717975 \\
\hline & 78 & Akv-EH & de novo DLBCL & 6 & 40821642 \\
\hline & 79 & Akv-CDH & Lymphoma, NOS & 6 & 40955151 \\
\hline & 80 & $\mathrm{Akv}-\mathrm{CDH}$ & PCT & 6 & 54425558 \\
\hline & 81 & Akv wt & FBL & 6 & 72441620 \\
\hline & 82 & Akv wt & РCT & 6 & 84016089 \\
\hline 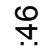 & 83 & Akv-CDH & Lymphoma, NOS & 6 & 88923549 \\
\hline & 84 & Akv-EH & DLBCL (from SMZL) & 6 & 99153396 \\
\hline$\hat{\circ}$ & 85 & Akv-CDH & Lymphoma, NOS & 6 & 113010477 \\
\hline ㅁำ & 86 & Akv-CD & DLBCL (from FBL) & 6 & 120535110 \\
\hline$\vec{D}$ & 87 & Akv-CD & Histiocytic sarcoma & 6 & 136905161 \\
\hline$\stackrel{8}{8}$ & 88 & Akv-CD & РCT & 6 & | 45079282 \\
\hline$\stackrel{?}{\stackrel{9}{s}}$ & 89 & $\mathrm{Akv}-\mathrm{CDH}$ & Plasma cell prolif. & 7 & $|884| 894$ \\
\hline อे & 90 & Akv wt & $\mathrm{FBL}$ & 7 & 24263292 \\
\hline$\stackrel{D}{0}$ & 91 & Akv wt & PCT & 7 & 28498093 \\
\hline
\end{tabular}

8043109

8043150

8043659

10214198

Notch2

Dph5

146091393

915327

PapssI

Bcllo

Mcoln2

Lrrc40

BC034239

AKI32816

Bach2

32619341
32702311

(4)734542

7933461

3699599

39921672

07966364

838640

29717975

(0955I5I

.

1620

23549

13010477

8841894

28498093

Pax5
Rad23b
Akap2
Nfia/D90I73
Fgr
DscrlI2
Pla2g2d
Hs3stl
TIrl
---
Gfil
Aldh2
Gnal2
463I427CI7Rik
BC048599
22I00I0C04Rik
ScrnI
BCI00525
Dysf
Gprl75
FoxpI
Thumpd3
Cecr5
Arhgdib
Lrmp
Apoc4
Xrccl
5830482F20Rik


Table 3: Positions of integrated proviruses in tumor DNA (Continued)

\begin{tabular}{|c|c|c|c|c|c|c|c|c|}
\hline 92 & Akv-EH & de novo DLBCL & 7 & 28691963 & Map4kl & $T$ & - & $\mathrm{T}$ \\
\hline 93 & Akv-EH & PCT & 7 & 29760852 & $Z f p \mid 4$ & 0 & $\mathrm{I}$ & - \\
\hline 94 & Akv-CD & Histiocytic sarcoma & 7 & 30746023 & Fxyd5 & 0 & 1 & - \\
\hline 95 & Akv wt & PCT & 7 & 45003648 & Flt3l & 0 & 1 & - \\
\hline 96 & Akv wt & DLBCL (from FBL) & 7 & 66812108 & Adamts 17 & 0 & 1 & - \\
\hline 97 & Akv wt & DLBCL (from FBL) & 7 & $7348 \mid 277$ & --- & 7 & - & - \\
\hline 98 & Akv-CD & SMZL & 7 & 76335733 & D430020FI6 & 0 & 1 & - \\
\hline 99 & Akv-EH & DLBCL (from FBL) & 7 & 79083435 & Mfge8 & 0 & $\mathrm{I}$ & - \\
\hline 100 & Akv-EH & РCT & 7 & 80764333 & AK034740 & 0 & $\mathrm{I}$ & - \\
\hline 101 & Akv wt & PCT & 7 & 82574727 & EftudI & I & - & $I^{*}$ \\
\hline 102 & Akv-EH & de novo DLBCL & 7 & 99422958 & Arrbl/mmu-mir-326 & 0 & $\mathrm{I}$ & - \\
\hline 103 & Akv wt & SBL & 7 & II 3972740 & Rras2/Copbl & 32 & - & - \\
\hline 104 & Akv-CDH & DLBCL (from FBL) & 7 & 121248057 & AK043969 & 0 & 1 & - \\
\hline 105 & Akv-EH & de novo DLBCL & 7 & 126957227 & Cd2bp2 & 2 & - & - \\
\hline 106 & Akv wt & DLBCL (from FBL) & 7 & $|32| 4745 \mid$ & 463I426J05Rik & 0 & 1 & - \\
\hline 107 & Akv-CD & DLBCL (from FBL) & 7 & $14474 \mid 729$ & Condl & 21 & - & - \\
\hline 108 & Akv-CD & SMZL & 8 & 8401964 & --- & 0 & I & - \\
\hline 109 & Akv-EH & DLBCL (from FBL) & 8 & 10980425 & --- & 4 & - & - \\
\hline 110 & Akv wt & $\mathrm{FBL}$ & 8 & 35575516 & Dctn6 & 0 & 1 & - \\
\hline 111 & Akv wt & PCT & 8 & 37098099 & --- & 0 & I & - \\
\hline 112 & Akv-CD & SMZL & 8 & 74527100 & Pgls & 3 & - & - \\
\hline 113 & Akv wt & DLBCL (from FBL) & 8 & 98522228 & Gins3 & 0 & 1 & - \\
\hline 114 & Akv wt & SBL & 8 & 112753504 & $\mathrm{BC} 027816$ & 0 & I & - \\
\hline 115 & Akv-EH & de novo DLBCL & 8 & 118119184 & Wwox & 1 & - & I \\
\hline 116 & Akv-EH & Lymphoma, NOS & 8 & 123611854 & Irf8 & I & - & - \\
\hline 117 & Akv-EH & DLBCL (from FBL) & 8 & 126312417 & Tubb3/Mela & I & - & I \\
\hline 118 & Akv wt & DLBCL (from FBL) & 8 & 126312418 & & & & \\
\hline 119 & Akv wt & PCT & 9 & 46235263 & --- & 0 & 1 & - \\
\hline 120 & Akv-CD & Abscess & 9 & $865 \mid 4607$ & A33004IJ22Rik & 0 & 1 & - \\
\hline 121 & Akv-CDH & PCT & 9 & 104103363 & Acpp & 1 & - & 1 \\
\hline 122 & Akv-EH & $\mathrm{FBL}$ & 9 & 115327386 & --- & 0 & 1 & - \\
\hline 123 & Akv wt & PCT & 9 & 117143474 & Rbms3 & 0 & 1 & - \\
\hline 124 & Akv-EH & PCT & 10 & 5056902 & Synel & 1 & - & - \\
\hline 125 & Akv wt & SBL & 10 & 7626524 & Map3k7ip2 & I & - & I \\
\hline 126 & Akv wt & FBL & 10 & 19681745 & Map3k5 & 2 & - & - \\
\hline 127 & Akv wt & PCT & 10 & 43100419 & Pdss2 & 0 & I & - \\
\hline 128 & Akv-EH & PCT & 10 & $5929556 I$ & Dnajb|2 & 2 & - & - \\
\hline 129 & Akv-CD & Histiocytic sarcoma & 10 & 75678805 & Prmt2 & 0 & I & - \\
\hline 130 & Akv wt & $\mathrm{FBL}$ & 10 & $774 \mid 2375$ & Pfkl & 0 & 1 & - \\
\hline$|3|$ & Akv wt & DLBCL (from FBL) & 10 & 8009951 & BC058238 & 2 & - & - \\
\hline 132 & Akv wt & $\mathrm{DLBCL}$ (from FBL) & 10 & 84366577 & Ric8b & 0 & 1 & - \\
\hline 133 & Akv-EH & de novo DLBCL & 10 & 87574719 & BC070476 & 0 & I & - \\
\hline 134 & Akv-EH & de novo DLBCL & 10 & 92501677 & Pctk2 & 1 & - & - \\
\hline 135 & Akv-CD & n.d. & 10 & 123752010 & --- & 0 & 1 & - \\
\hline 136 & Akv-CDH & PCT & II & 3236433 & I500004A08Rik & 0 & 1 & - \\
\hline 137 & Akv wt & PCT & 11 & 5331124 & AKI33342 & 0 & I & - \\
\hline 138 & Akv wt & DLBCL (from FBL) & 11 & 23587218 & 4933435A I 3Rik & 4 & - & - \\
\hline
\end{tabular}


Table 3: Positions of integrated proviruses in tumor DNA (Continued)

\begin{tabular}{|c|c|c|c|c|c|c|c|c|}
\hline 139 & Akv-CD & DLBCL (from FBL) & $T 1$ & 23587651 & & & & \\
\hline 140 & Akv wt & PCT & 11 & 32443618 & Stk 10 & I & - & 1 \\
\hline$|4|$ & Akv wt & PCT & 11 & 46693128 & Timd4 & 0 & 1 & - \\
\hline 142 & Akv-CD & PCT & 11 & 51687729 & Phfl5 & 0 & 1 & - \\
\hline 143 & Akv-EH & de novo DLBCL & 11 & 62648918 & Trim 16 & 0 & I & - \\
\hline 144 & Akv wt & PCT & 11 & 67380781 & Gas7 & 0 & I & - \\
\hline 145 & Akv-EH & de novo DLBCL & 11 & 74962635 & Smg6 & 9 & - & - \\
\hline 146 & Akv-EH & de novo DLBCL & 11 & 78821537 & Ksrl & 0 & I & - \\
\hline 147 & Akv-EH & РCT & 11 & 86862765 & GdpdI & 0 & I & - \\
\hline 148 & Akv wt & DLBCL (from FBL) & 11 & 95031687 & Tac4 & 0 & I & - \\
\hline 149 & Akv-EH & de novo DLBCL & 11 & 102249514 & Grn & 0 & I & - \\
\hline 150 & Akv wt & DLBCL (from FBL) & 11 & 102990732 & Fmnll & 2 & - & - \\
\hline$|5|$ & Akv wt & DLBCL (from FBL) & 11 & 106946907 & Noll I & 0 & 1 & - \\
\hline 152 & Akv-CD & Abscess & 11 & 107232889 & Pitpncl & 1 & - & 1 \\
\hline 153 & Akv-EH & $\mathrm{PCT}$ & 11 & 116126666 & Exoc7 & 0 & I & - \\
\hline 154 & Akv-CDH & Lymphoma, NOS & 11 & | | 8058083 & Pscd I & 1 & - & $I^{*}$ \\
\hline 155 & Akv-CD & SMZL & 12 & 3288080 & Rablo & 0 & I & - \\
\hline 156 & Akv wt & PCT & 12 & 13172238 & Ddxl & 0 & 1 & - \\
\hline 157 & Akv-CD & Abscess & 12 & 56600484 & Garnll & 0 & 1 & - \\
\hline 158 & Akv-EH & de novo DLBCL & 12 & 77286036 & Zbtb25 & 1 & - & I \\
\hline 159 & Akv wt & DLBCL (from FBL) & 12 & 80214408 & AKI32344 & i & - & I \\
\hline 160 & Akv wt & DLBCL (from FBL) & 12 & 86569587 & Batf & 2 & - & - \\
\hline 161 & Akv-CD & DLBCL (from FBL) & 12 & 113688885 & BC004786 & 5 & - & - \\
\hline 162 & Akv wt & PCT & 13 & 24453563 & Cmah & 1 & - & $I^{*}$ \\
\hline 163 & Akv-CDH & DLBCL (from FBL) & 13 & 28624333 & --- & 0 & 1 & - \\
\hline 164 & Akv wt & PCT & 13 & 28727388 & --- & 3 & - & - \\
\hline 165 & Akv-CDH & DLBCL (from FBL) & 13 & 28764182 & & & & \\
\hline 166 & Akv-CDH & DLBCL (from FBL) & 13 & 28950798 & Sox4 & 79 & - & - \\
\hline 167 & Akv-CD & DLBCL (from FBL) & 13 & 28950905 & & & & \\
\hline 168 & Akv-EH & de novo DLBCL & 13 & 28955972 & & & & \\
\hline 169 & Akv wt & DLBCL (from FBL) & 13 & 28958981 & & & & \\
\hline 170 & Akv-EH & DLBCL (from FBL) & 13 & 30695323 & Dusp22 & 4 & - & - \\
\hline $17 \mid$ & Akv-CD & Histiocytic sarcoma & 13 & 30727958 & & & & \\
\hline 172 & Akv wt & РCT & 13 & 31914670 & Gmds & 1 & - & 1 \\
\hline 173 & Akv-CD & SMZL & 13 & $362 \mid 4883$ & Fars2 & 0 & I & - \\
\hline 174 & Akv wt & PCT & 13 & 37804150 & Rrebl & 8 & - & - \\
\hline 175 & Akv-CD & Histiocytic sarcoma & 13 & 38701503 & Eeflel & 1 & - & - \\
\hline 176 & $A k v-C D$ & $\mathrm{DLBCL}$ (from $\mathrm{FBL}$ ) & 13 & 43205444 & GfodI & 1 & - & I* \\
\hline 177 & $A k v-C D$ & SMZL & 13 & 63488458 & Fancc & 4 & - & - \\
\hline 178 & Akv wt & DLBCL (from FBL) & 13 & 84050271 & Mef2c & 11 & - & - \\
\hline 179 & Akv-CDH & DLBCL (from FBL) & 14 & 6779744 & Dnasell3 & 1 & - & I \\
\hline 180 & Akv-CDH & Lymphoma, NOS & 14 & 24439077 & Rail7 & 10 & - & - \\
\hline 181 & Akv-CDH & PCT & 14 & 25348097 & Slmap & 1 & - & I \\
\hline 182 & Akv-EH & Lymphoma, NOS & 14 & 29013598 & Cacnald & 0 & I & - \\
\hline 183 & Akv wt & SBL & 14 & 30491074 & $\mathrm{Btd}$ & 0 & I & - \\
\hline 184 & Akv wt & DLBCL (from FBL) & 14 & $5948|89|$ & --- & 0 & 1 & - \\
\hline 185 & Akv wt & $\mathrm{FBL}$ & 14 & 59637396 & AKI5I394 & 3 & - & - \\
\hline
\end{tabular}


Table 3: Positions of integrated proviruses in tumor DNA (Continued)

\begin{tabular}{|c|c|c|c|c|c|c|c|c|}
\hline 186 & Akv-EH & de novo DLBCL & 14 & 63115780 & Msra & 1 & - & $T^{*}$ \\
\hline 187 & Akv wt & PCT & 14 & 72420139 & Sucla2 & 0 & 1 & - \\
\hline 188 & Akv wt & SMZL & 14 & 113921088 & microRNA cluster & 2 & - & - \\
\hline 189 & Akv wt & FBL & 15 & 57752356 & BC066830 & 0 & I & - \\
\hline 190 & Akv-CD & SMZL & 15 & 58238320 & 15 Ertd62le & 0 & I & - \\
\hline 191 & Akv wt & PCT & 15 & 61240727 & --- & 0 & I & 1 \\
\hline 192 & Akv wt & PCT & 15 & 61240729 & & & & \\
\hline 193 & Akv wt & FBL & 15 & 73548838 & Gpr20/Ptp4a3 & 6 & - & - \\
\hline 194 & Akv-EH & DLBCL (from FBL) & 15 & 79567673 & Unc84b & 4 & - & - \\
\hline 195 & Akv wt & DLBCL (from FBL) & 15 & 79728346 & Apobec3 & 0 & 1 & - \\
\hline 196 & Akv-EH & Plasma cell prolif. & 15 & 90445122 & Cpne8 & 1 & - & - \\
\hline 197 & Akv wt & $\mathrm{FBL}$ & 16 & 23906462 & $\mathrm{Bcl} 6$ & 5 & - & - \\
\hline 198 & Akv-EH & de novo DLBCL & 16 & 24049008 & --- & 5 & - & - \\
\hline 199 & $A k v-C D$ & DLBCL (from FBL) & 16 & 24086635 & & & & \\
\hline 200 & Akv-EH & DLBCL (from FBL) & 16 & 24101470 & & & & \\
\hline 201 & Akv-EH & Lymphoma, NOS & 16 & 24152772 & & & & \\
\hline 202 & Akv wt & $\mathrm{FBL}$ & 16 & 24178252 & & & & \\
\hline 203 & Akv wt & DLBCL (from FBL) & 16 & 32049420 & Lrrc33 & 3 & - & - \\
\hline 204 & Akv-CD & n.d. & 16 & 52388367 & Alcam & 1 & - & 1 \\
\hline 205 & Akv wt & PCT & 17 & 6624877 & Vil2 & 3 & - & - \\
\hline 206 & Akv wt & PCT & 17 & 11630998 & Park2 & 1 & - & I* \\
\hline 207 & Akv wt & DLBCL (from FBL) & 17 & 36597927 & $2410137 M \mid 4 R i k$ & 0 & 1 & - \\
\hline 208 & Akv wt & FBL & 17 & 49537999 & 23 I00I5N2IRik & 1 & - & $I^{*}$ \\
\hline 209 & Akv-EH & DLBCL (from FBL) & 17 & 63705275 & Fert2 & 0 & 1 & - \\
\hline 210 & Akv-CD & SMZL & 17 & 71389894 & Kntc2 & 0 & 1 & - \\
\hline 211 & Akv-CDH & PTLL & 17 & $746 \mid 4066$ & Birc6 & 1 & - & - \\
\hline 212 & Akv wt & PCT & 18 & 11242422 & --- & 0 & 1 & - \\
\hline 213 & Akv-CD & SMZL & 18 & 12368360 & $\mathrm{Npcl}$ & 1 & - & 1 \\
\hline 214 & Akv-CD & SMZL & 18 & 36016553 & Cxxc5 & 3 & - & - \\
\hline 215 & Akv-CDH & DLBCL (from FBL) & 18 & 39790170 & --- & 0 & 1 & - \\
\hline 216 & Akv wt & FBL & 18 & 42916219 & Ppp2r2b & 0 & i & - \\
\hline 217 & Akv-EH & de novo DLBCL & 18 & 60930595 & $\mathrm{li} / \mathrm{Cd} 74$ & 0 & 1 & 1 \\
\hline 218 & Akv-EH & DLBCL (from FBL) & 18 & 60930793 & & & & \\
\hline 219 & Akv-CD & DLBCL (from FBL) & 18 & 60930833 & & & & \\
\hline 220 & Akv wt & PCT & 18 & 60931233 & & & & \\
\hline 221 & Akv-CDH & PCT & 18 & 60934151 & & & & \\
\hline 222 & Akv wt & DLBCL (from FBL) & 18 & 61103722 & Camk2a & 0 & 1 & - \\
\hline 223 & Akv-EH & РCT & 18 & 65601468 & Maltl & I & - & - \\
\hline 224 & Akv wt & DLBCL (from FBL) & 18 & 67824697 & Ptpn2 & 0 & 1 & - \\
\hline 225 & Akv wt & $\mathrm{FBL}$ & 19 & 11607493 & Ms4a4d & 0 & I & - \\
\hline 226 & Akv wt & DLBCL (from FBL) & 19 & 34362400 & Fas & 2 & - & - \\
\hline 227 & Akv-EH & de novo DLBCL & 19 & 37505125 & Hhex/Exoc6 & 44 & - & - \\
\hline 228 & Akv-CD & DLBCL (from FBL) & 19 & 37532944 & & & & \\
\hline 229 & Akv-EH & de novo DLBCL & 19 & 37537038 & & & & \\
\hline 230 & Akv-CD & SMZL & 19 & 37560104 & & & & \\
\hline 231 & Akv-CD & Histiocytic sarcoma & 19 & 37560104 & & & & \\
\hline 232 & Akv-EH & PCT & 19 & 4347487I & Cnnml & 0 & 1 & - \\
\hline
\end{tabular}


Table 3: Positions of integrated proviruses in tumor DNA (Continued)

\begin{tabular}{|c|c|c|c|c|c|c|c|c|}
\hline 233 & $\mathrm{Akv-CDH}$ & PCT & 19 & 47583866 & Obfcl & 0 & $T$ & - \\
\hline 234 & Akv wt & DLBCL (from FBL) & 19 & 47963460 & AK0I458I & 0 & I & - \\
\hline 235 & Akv wt & PCT & 19 & 53994934 & Shoc2 & 0 & 1 & - \\
\hline 236 & Akv wt & FBL & 19 & 55633727 & Vtila & I & - & I* \\
\hline 237 & Akv wt & FBL & $x$ & |0329353| & P2rylo & 0 & I & - \\
\hline 238 & Akv-CDH & Lymphoma, NOS & $x$ & 109985132 & Dach2 & I & - & 1 \\
\hline 239 & Akv-EH & DLBCL (from FBL) & $x$ & 129928954 & Btk & 0 & I & - \\
\hline 240 & Akv wt & DLBCL (from FBL) & $x$ & 162452646 & Tmsb4x & 1 & - & 1 \\
\hline
\end{tabular}

aThe gene (or RefSeq) closest to the integrated provirus is given (UCSC, mouse mm8 assembly). --- indicates that the distance to the closest gene/RefSeq is more than I00 kb.

bFor each insertion, it is indicated, based on RTCGD $(\mathrm{mm} 8)$, whether a novel RIS has been defined.

cFor each insertion, it is indicated, based on RTCGD (mm8), whether a novel CIS has been defined. The definition follows the recommendations from RTCGD with a window size of $100 \mathrm{~kb}, 50 \mathrm{~kb}$, and $30 \mathrm{~kb}$ for ClSs with 4 (or more), 3, or 2 insertions, respectively. * indicates an exception from this rule, if two integration sites are found within the same gene/RefSeq.

n.d., not determined.

Table 4: Frequency of proviral insertions within defined genomic regions

\begin{tabular}{|c|c|c|c|c|c|c|c|c|c|c|c|c|c|c|c|}
\hline \multirow[t]{2}{*}{ Virus } & \multicolumn{2}{|l|}{ Upstream $^{a}$} & \multicolumn{2}{|l|}{ Promoterb } & \multicolumn{2}{|l|}{ I. intron } & \multicolumn{2}{|l|}{$\begin{array}{c}\text { Internal } \\
\text { intron }\end{array}$} & \multicolumn{2}{|l|}{$\begin{array}{c}\text { Last } \\
\text { intron }\end{array}$} & \multicolumn{2}{|l|}{ Downstreamc } & \multicolumn{2}{|l|}{ Exon } & \multirow[t]{2}{*}{ Outside $^{d}$} \\
\hline & + & - & + & - & + & - & + & - & + & - & + & - & + & - & \\
\hline Akv-wt & $2 / 1042 \%$ & $7 / 1047 \%$ & $5 / 1045 \%$ & $3 / 1043 \%$ & $9 / 1049 \%$ & $16 / 104 \mid 5 \%$ & $6 / 1046 \%$ & $17 / 10416 \%$ & $2 / 1042 \%$ & I/I04 I\% & $5 / 1045 \%$ & 8/104 8\% & $2 / 1042 \%$ & I/104 I\% & $11 / 10410 \%$ \\
\hline Akv-CD & $3 / 467 \%$ & $6 / 4613 \%$ & $1 / 462 \%$ & $0 / 460 \%$ & $3 / 467 \%$ & $5 / 4611 \%$ & $2 / 464 \%$ & $8 / 4617 \%$ & $0 / 460 \%$ & $0 / 460 \%$ & $4 / 469 \%$ & $6 / 4613 \%$ & | /46 2\% & $0 / 460 \%$ & $5 / 46 । 1 \%$ \\
\hline Akv-EH & $3 / 516 \%$ & $4 / 518 \%$ & $1 / 512 \%$ & $0 / 510 \%$ & $4 / 518 \%$ & $6 / 5112 \%$ & $2 / 5 \mid 4 \%$ & $11 / 5 \mid 22 \%$ & $2 / 514 \%$ & $0 / 510 \%$ & $7 / 5114 \%$ & |/5| $2 \%$ & $2 / 514 \%$ & $2 / 514 \%$ & $6 / 5112 \%$ \\
\hline Akv-CDH & $1 / 393 \%$ & $2 / 395 \%$ & $2 / 395 \%$ & $3 / 398 \%$ & $7 / 3918 \%$ & $3 / 398 \%$ & $3 / 398 \%$ & $5 / 3913 \%$ & $0 / 390 \%$ & $1 / 393 \%$ & $5 / 3913 \%$ & $4 / 39 \quad 10 \%$ & $0 / 390 \%$ & $0 / 390 \%$ & $3 / 398 \%$ \\
\hline Total & $9 / 2404 \%$ & $19 / 2408 \%$ & $9 / 2404 \%$ & $6 / 2403 \%$ & $23 / 24010 \%$ & $30 / 24013 \%$ & $13 / 2405 \%$ & $4 \mid / 24017 \%$ & $4 / 2402 \%$ & $2 / 2401 \%$ & $2 \mathrm{I} / 2409 \%$ & $19 / 2408 \%$ & $5 / 2402 \%$ & $3 / 240$ I\% & $25 / 24010 \%$ \\
\hline
\end{tabular}

a Within 3-100 kb upstream of target gene/RefSeq

b Within $0-3 \mathrm{~kb}$ upstream of exonl of target gene/RefSeq

cWithin $100 \mathrm{~kb}$ downstream of target gene/RefSeq

d Proviral integrations $>100 \mathrm{~kb}$ away from gene/RefSeq

+ or - denotes the orientation of the integrated provirus relative to the target gene/RefSeq. 
integration sites with each other as well as with previously defined RISs in RTCGD. In principle, using the recommendations from RTCGD with a window size of $100 \mathrm{~kb}$, $50 \mathrm{~kb}$, and $30 \mathrm{~kb}$ for CISs with 4 (or more), 3, or 2 insertions, respectively, we were hereby able to define 35 novel common integration sites (CISs) (Table 3). Just a single one of these could be correlated with a specific diagnosis and with a specific virus, since in two independently Akvwt induced plasmacytomas a definite region of chromosome 15 was targeted. However, this region does not contain genes/RefSeqs within a $100 \mathrm{~kb}$ distance from the integrated proviruses, so for the present we cannot predict what - if any - candidate gene(s) that might have been influenced by the integrated proviruses. For the remaining 34 CISs more than one virus and more than one tumor diagnosis were implicated, which implies that no straightforward association between target gene (and/or causative virus) and tumor type can be deduced.

In six cases, the same chromosomal locus was targeted several times. These cases include Bach2 (hit 4 times), Sox4 (hit 4 times), Hhex (hit 5 times), Ii (hit 5 times), a region of chr. 16 not containing any genes/RefSeqs within a distance of $100 \mathrm{~kb}$ from the integration sites (hit 5 times), and LOC433632 (hit 7 times). Five of these integration sites were already registered in RTCGD, only the $\mathrm{I} i$ locus define a completely novel RIS/CIS. This latter finding may suggest that $I i$ targeting is strongly associated with the applied model system (virus/mouse strain)[27]. We also note that an integration has taken place within the first intron of Stk10 in a plasmacytoma induced by Akv-wt (Table 3, \#140), which appears to be in conflict with the work of Shin et al., 2004 [28] where Stk10 was described as a SMZL specific candidate gene.

Finally, we examined if specific regions of the targeted gene/RefSeq have been favored with respect to orientation and position of the integrated provirus. We have recently reported of differences between Akv MLV and an enhancer mutant hereof, Akv1-99, in their patterns of proviral insertions around host transcription units in the induced tumors [29]. In line with this, it might be envisioned that destroying the alternative splice sites of the virus could lead to a different pattern of integration site selection during tumorigenesis; e.g. it might be speculated if particular positions relative to the target gene somehow would facilitate gene deregulation dependent on the presence or absence of intact SA' and/or SD' sites. Accordingly, we allocated each individual integration site position and orientation to a defined region, i.e. either upstream, within the promoter, within 1. intron, within last intron, within all other introns, within exons, or downstream of the target gene (Table 4). Eleven cases in total were excluded as they were positioned - almost with the same distance - in between two target genes, upstream of one and down- stream of the other. As seen in table 4, no clear differences with respect to the four viruses were observed, signifying that mutations of the alternative splice sites do not have major effect on the ability of the Akv MLV to affect the target gene/RefSeq from certain positions and/or orientations. It might be worth to notice that the overall picture shows that about half of all integrations are found within introns, and among these there appear to be a tendency for a provirus orientation opposite to that of the target gene. In these cases the formation of chimeric RNA species by promoter insertion and/or splicing would not be predicted.

\section{Discussion}

We have in the B-lymphomagenic Akv MLV identified a novel exon, which is defined by the alternative splice acceptor (SA') and the splice donor (SD') sites located in the capsid encoding region. While previous studies of Moloney and Friend MLV have demonstrated production of a $4.4 \mathrm{~kb}$ transcript using the same SD' site together with the canonical env SA site, this is the first report demonstrating the existence of an alternative SA' site and production of a double-spliced transcript during the life cycle of a replication-competent simple retrovirus. Yet it remains to be investigated how widespread this competence is. An alignment between six murine retroviruses shows that the conserved splice junction dinucleotide AG is present neither in Cas-Br-E nor in Moloney MLV, although the region in general is well-conserved (Fig. 6).

We did not perform detailed analyses of the influence of the splice site mutations on the viral replication. However, since the same number $\left(10^{5}\right.$ to $\left.10^{6}\right)$ of infectious virus particles, as measured by infectious center assays, were injected from each virus series, and since the mutant viruses induced tumors with comparable incidences and latencies as the wild-type virus, it is not likely that the mutations had imposed severe weakening on the in vivo spreading capability. Hence the observed shifts in specificity of the induced tumors most likely are a direct result of the introduced mutations. However, we note that Houzet

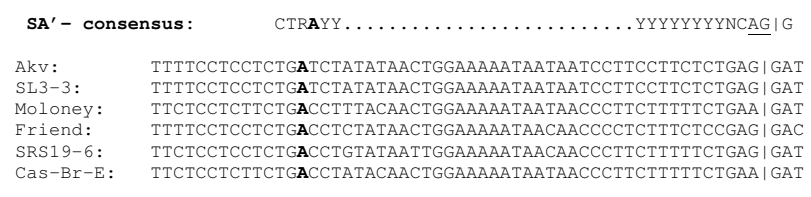

Figure 6

DNA sequence alignment around the Akv MLV SA' site in the capsid-coding region of a series of different ecotropic MLVs. The 3' splice acceptor site consensus sequences are shown on top, with the border of the novel gag exon indicated by a vertical line. The boldfaced $A$ in the sequence indicates the presumed branch point. 
et al. [19] observed a reduction in titer of SD'-mutants of Friend virus.

The in vivo significance of the alternative splice sites was exposed by a change of the oncogenic properties of Akv $\mathrm{MLV}$, when synonymous mutations destroying the SA' site, the SD' site, or both sites simultaneously were introduced. First and foremost, the obvious capability of Akv MLV to induce follicular B cell lymphoma was seriously weakened, when one or both of the alternative splice sites were mutated, suggesting that this competence relies on intact $\mathrm{SA}^{\prime}$ and SD' sites and a proper balance between all the produced transcripts (one full-length, two singlespliced, and one double-spliced). The integrity of Akv MLV seems fundamental for its capability to induce FBL; thus we just reported that Akv MLVs with mutated enhancer sequences retained the ability to induce tumors of B-cell type, but altered specificities were observed, including an impaired ability of FBL induction [11]

A more complex picture was observed regarding the strong predisposition of Akv MLV for plasmacytoma induction. This predisposition was affected significantly only if the SA' alone was mutated. Thus, if the SD' site was mutated along with SA', wild-type potential was restored. This may indicate that the ability to induce plasmacytoma is dependent on a fine-tuned balance between the alternative single-spliced and double-spliced transcripts. If no double-spliced transcript is produced, while the singlespliced $4.4 \mathrm{~kb}$ transcript still is, as is the case for the SA' mutant, the single-spliced transcript somehow seems to be related with a barrier for plasmacytoma induction. On the other hand, if both transcripts are produced (Akv-wt) or none of them are produced (the $\mathrm{SA}^{\prime} / \mathrm{SD}^{\prime}$ double mutant) the virus will hold a potential for inducing plasmacytomas. This is in line with the overall observation that the most pronounced effects were observed when the SA' or SD' splice sites were mutated individually, while the outcome of infection with the SA'/SD' double mutant in essence, except for the capability of FBL induction, was comparable to that of the wild-type virus. It may thus be speculated if a delicate balance between the alternatively single-spliced and double-spliced transcripts is a key determinant for the shift in oncogenic specificity, as demonstrated by the SA' and SD' splice site Akv mutants.

The most striking shifts in specificity observed were the increased tendency to stimulate development of splenic marginal zone lymphoma and the exposure of a novel ability for inducing histiocytic sarcoma for the SA' site mutant. Although we have shown that mutation of the SA' site results in inhibition of generation of the doublespliced product, we are at this point not able to explain or point to any detailed mechanisms underlying the observed changes in specificity. The other remarkable shift in specificity was detected with the SD' mutant, which was the only virus capable of inducing centroblastic DLBCL, i.e. tumors for which an origin from the follicle or marginal zone could not be inferred and comparable to de novo DLBCL in humans. Moreover, since the exposed potential appeared quite strong (35\% of the SD'-mutant induced tumors fell within this diagnosis), and since such tumors are in general rare in mice, this mutant virus may be a helpful starting point tool to create a solid mouse model of human de novo DLBCL.

Obviously, the proposed significance of proper balances between the four different transcripts for the observed shifts in tumor specificity may reflect a need for a well-regulated balance between resulting translational products. We did not investigate if novel proteins were produced, but the open reading frames (ORFs) of both the alternatively singly and doubly spliced transcripts clearly reveal a potential for additional proteins to be produced. The gene products of the single-spliced $4.4 \mathrm{~kb}$ transcript most probably correspond to the $\mathrm{p} 50$ and $\mathrm{p} 60$ proteins made from the equivalent Friend MLV transcript [19]. These proteins were produced with translation initiations at two initiation codons (AUGgag and CUGglyco-gag) in the same ORF and were shown to harbor the N-terminal Gag domain including matrix, p12, and the first 110 amino acids of the capsid in frame with the last 116 amino acids of integrase [19]. Also the smaller double-spliced transcript harbors smaller ORFs providing a scene for even more MLV proteins.

Intragenic elements such as gag enhancers have been known for many years in avian retroviruses $[30,31]$. However, it seems unlikely that a similar element is involved here, since the mutant virus with $\mathrm{SA}^{\prime}$ and $\mathrm{SD}^{\prime}$ sites mutated together was clearly the less affected one. This observation, in concert with the observed consequence on generation of different splice products, more likely suggests that the effect on disease specificity is related to an RNA processing phenomenon rather than an intragenic gag determinant with an effect on transcription.

Lymphoma-induction by non-acute murine retroviruses is associated with multiple proviral insertions that affect critical host genes. To achieve such multiple insertions the superinfection resistance caused by Env-expression must be by-passed. One possibility could be that reduced Envexpression caused by mutation of the gag splice sites as reported here might favor superinfection and thereby multiple proviral insertions. While we cannot exclude this possibility, our finding of the same number of sequence tags for proviral insertions for the wild-type and mutated viruses gives no immediately support to such a mechanism. 
Retroviral insertional mutagenesis has been established as a solid strategy for the identification of candidate cancercausing genes [6,26,32-34]. Accordingly, in an effort to relate specific genes or pathways with specific diagnoses, splice pattern, or causative virus, we identified a pool of 240 integration sites from which 111 novel RISs and 35 novel CISs were defined. Our analyses did not immediately point to any clear correlations; nevertheless the collection of candidate genes may prove to be a central input in future attempts to understand the exact roles of the different splice transcripts and/or their resulting translational products in hematopoietic differentiation and tumorigenesis.

\section{Conclusion}

We have in the B-lymphomagenic Akv MLV in the gag region identified a novel exon, which represents the first example of a doubly spliced gammaretroviral transcript. Mutations of the alternative splice sites that define this novel transcript change the distribution of the different induced tumor phenotypes as well as generate tumors of additional specificities such as de novo diffuse large B cell lymphoma and histiocytic sarcoma. Provirus integration site analyses revealing 111 novel RISs and 35 novel CISs did not clearly point to specific target genes or pathways to be associated with specific tumor diagnoses or individual viral mutants. However, the list of potential target genes will be useful for future studies of hematopoietic differentiation and tumorigenesis.

\section{Methods}

\section{Exon trapping}

Exon trapping was performed by using an Exon Trapping System kit (GibcoBRL) in essence according to supplied protocol. In brief, Akv DNA was digested with BamHI or $B g l$ II and all restriction fragments were subcloned into the pSPL3 plasmid, which in addition to sequences necessary for replication and growth in Escherichia coli contains SV40 sequences that provide for replication and transcription in COS-7 cells, splicing signals, and a multiple cloning site. Following transformation into E. coli, plasmid DNA was isolated and transfected into COS-7 cells. Total RNA was isolated from cultured cells and used for firststrand cDNA synthesis. The CDNA was PCR amplified in two rounds with primers located in the vector exons. The outcome of the PCR amplifications was several different fragments, which were all sequenced. Two of trapped sequences could be verified as exons by RT-PCR analyses of RNA isolated from Akv MLV infected cells. The two trapped exons were defined by the same splice acceptor site (SA', located in the gag region, Fig. 1), but by different splice donor sites (SD' and SD*, Fig. 1), and the sizes were $235 \mathrm{bp}$ and $180 \mathrm{bp}$, respectively.

\section{Generation of viruses}

The mutations of Akv MLV at splice acceptor (SA') and/or splice donor site (SD') sites were introduced by PCR-based oligonucleotide directed mutagenesis using the following primers harboring the wanted mutations (underlined): Mut-C: 5'-CTATATAACTGGAAAAATAATAATCCÁTCĀTTCAGTGAAGATCCAGGTAAACT-3', Mut-D: 5'GGATTATTATTTTTCCAGTTATATAGATCGCTGGAG-

GAAAACG-3', and Mut-H: 5'-TTGGGATTACACCACCCAAAGGGGACGAAACCACCT-3'. A 720 bp Bsu36I Bsu36I fragment harboring the mutations was cloned into the full length parental provirus. The correct sequence of the introduced $\mathrm{Bsu} 36 \mathrm{I}$ fragment was verified by sequence analysis.

\section{Pathogenicity experiments}

Akv wild-type virus $\lambda 623$ and the three different alternative splice site mutant viruses, Akv-CD, Akv-EH, and Akv$\mathrm{CDH}$, mutated in either the SA' or SD' site, or in both sites simultaneously, were injected into newborn mice of the inbred NMRI strain, as described in details [35]. Control mice of the same colony were mock injected with $0.1 \mathrm{~mL}$ complete medium. The animals were monitored 5 days per week. Mice were sacrificed and autopsied when showing signs of illness or tumor development. Tumor development was diagnosed on the basis of grossly enlarged lymphoid organs after having reached the size described earlier, which is compatible with lymphoma [36]. Lymphoid tumor tissues and the liver were dissected, stored frozen $\left(-80^{\circ} \mathrm{C}\right)$ and/or fixed in formalin for further analysis. Statistical analysis was carried out using the two-tailed Fisher's exact test.

\section{Histopathological examination and immunohistochemical analysis}

Formalin-fixed, paraffin-embedded sections from lymph nodes, thymus, spleen and liver were analyzed. Three-tofive micrometer-thick sections were cut and stained with hematoxylin and eosin (H\&E), and when indicated with Giemsa, PAS or chloroacetate esterase. Tumors were classified according to the Bethesda proposals for classification of murine hematopoietic neoplasms [22,37]. Immunohistochemistry was performed on an automated immunostainer (Ventana Medical System, Inc.; AZ, USA), according to the protocol provided by the company with minor modifications. After deparaffinization and rehydration, the slides were placed in a microwave pressure cooker in $0.01 \mathrm{M}$ citrate buffer ( $\mathrm{pH} 6.0$ ), containing $0.1 \%$ Tween-20 and heated in a microwave oven at maximum power for $30 \mathrm{~min}$. After cooling in Tris-buffered saline, the sections were incubated with $3 \%$ goat or rabbit serum for $20 \mathrm{~min}$. The antibody panel used included CD3, CD79acy, TdT, myeloperoxidase (Dako, Hamburg, Germany), B220/CD45R and MAC3 (BD Pharmingen, NJ, 
USA). Appropriate positive controls were used to confirm the adequacy of the staining.

\section{Northern blot analysis}

Total cellular RNA was extracted from chronically infected NIH 3T3 cells by Trizol Reagent (Invitrogen), following the manufacturer's recommendations. Approximately 25 $\mu \mathrm{g}$ of RNA from each series (Akv-wt, Akv-CD, Akv-EH, Akv-CDH, and mock-infected cells) was size-fractionated on a $1.2 \%$ formaldehyde/agarose gel, and transferred to a nylon filter membrane (Zeta-Probe GT; Bio-Rad) under alkaline conditions $(50 \mathrm{mM} \mathrm{NaOH})$. Prehybridzation, hybridization, and washing procedures were according to standard protocol described in the instruction manual from Zeta-Probe GT [(pre)hybridization buffer: $0.25 \mathrm{M}$ sodium phosphate, $\mathrm{pH} 7.2,7 \%$ SDS, and washing buffers: $20 \mathrm{mM}$ sodium phosphate, ph 7.2, 5\% (1\%) SDS). The hybridization probes were a ${ }^{32} \mathrm{P}$ random priming labeled envelope specific probe (a $330 \mathrm{bp} \mathrm{SmaI} \mathrm{fragment} \mathrm{of} \mathrm{Akv}$ MLV (positions 6240to 6570) [38]]) and a $32 \mathrm{P}$ random priming labeled gag specific probe covering the novel exon. The gag probe was a 380 bp PCR-fragment amplified by the following primers: gag-forward: 5'-ATGGTCAGTTGCAGTACTGGCCGT-3' and gag-reverse: 5'TGGGGCTTCGGCCCGCGTTTTGGA-3'. The integrity and concentration of the RNA were confirmed by visual inspection of ethidium bromide-stained $18 \mathrm{~S}$ and $28 \mathrm{~S}$ rRNAs.

\section{$P C R$ and RT-PCR analyses}

Genomic DNA was purified from frozen tumor tissues by DNeasy Tissue Kit (Qiagen). Conservation of the introduced mutations was examined by PCR amplifying the region enclosing the mutations and by using the primers depicted in Fig. 1 (primer sequences and positions in Akv provirus: Forward primer, 5'-CCTATGAACCCCCTCCGTGGGTCA-3', nucleotides 1387-1410, and Reverse primer, 5'-TATTAAAGATCCTTTCGGCTTC-3', nucleotides 24122390). The resulting PCR products were analyzed by agarose gel electrophoresis, purified, and sequenced with nested sequencing primers (numberings refer to positions in Akv provirus). Forward primer, 5'-CGGGGAGGAGAAGCAGCGGGTGCT-3', nucleotides 1952-1976, and Reverse primer, 5'-GTCCCTAATAATTGCTGGCAAT-3', nucleotides 1942-1921.

For the RT-PCR analyses, total cellular RNA was extracted from tumor tissues or chronically infected NIH 3T3 cells by Trizol Reagent (Invitrogen), following the manufacturer's recommendations. 1-5 $\mu \mathrm{g}$ total RNA was used to make first-strand cDNA by First-Strand cDNA Synthesis Kit (Amersham Biosciences) with an oligo-dT primer. This was followed by standard PCR amplification using four different primer sets, \#1 to \#4. Primer set \#1: Forward primer, 5'-CCGACCCACCGTCGGGAGGAT-3', and reverse primer, 5'-CCTCATCAAACAGGGTGGGACT-3'. Primer set \#2: Forward primer, 5'-CCGACCCACCGTCGGGAGGAT-3', and reverse primer, 5'-CACCCACACGGAGTCTCCAAT-3'. Primer set \#3: Forward primer, 5'GATTACACCACCCAAAGAGCTC-3', and reverse primer, 5'-CACCCACACGGAGTCTCCAAT-3'. Primer set \#4 (env transcript): Forward primer, 5'-TTGGAGACCCCCGCCCAGGGACCACC-3', and reverse primer, 5'CACCCACACGGAGTCTCCAAT-3'. The resulting RT-PCR products were analyzed by agarose gel electrophoresis, and in most cases purified and sequenced.

\section{Provirus tagging and analyses}

Genomic DNA isolated from the induced tumors was analyzed for provirus integration sites by a splinkerette-based PCR method [26], described in details in [39]. The resulting host/virus junction fragments were sequenced, and the cellular flanking sequences were compared (BLAT search) to the UCSC Genome Browser, version mm8, to determine the chromosomal position of the integrated provirus. To identify possible novel retrovirus integration sites (RISs) and common integration sites (CISs), the individual integration sites were concomitantly matched up to the Retroviral Tagged Cancer Gene Database (RTCGD), version $\mathrm{mm} 8[24,25]$. The definition of a CIS follows the recommendations from RTCGD with a window size of $100 \mathrm{~kb}, 50 \mathrm{~kb}$, and $30 \mathrm{~kb}$ for CISs with 4 (or more), 3, or 2 insertions, respectively. Exception from the recommended window sizes was allowed in a few cases when two (or more) integrations were found within the same gene/RefSeq (Table 3 ).

\section{DNA sequencing analysis}

Amplified PCR products or purified plasmid preparations were sequenced with the DYEnamic ET terminator cycle sequencing kit (Amersham Pharmacia Biotech), following the manufacturer's recommendations, and reaction products were analyzed on an automated DNA sequencer (Applied Biosystems Inc.).

\section{Authors' contributions}

ABS and AHL carried out the molecular genetic studies (virus generation, exon trapping, PCR and RT-PCR analyses, northern analysis), and ABS drafted the manuscript. SK, LQM, and JS carried out pathogenicity experiments, and histopathological and immunohistochemical analyses. BW and MW carried out provirus tagging analyses. $\mathrm{ABS}, \mathrm{AHL}$, and FSP conceived of the study, and participated in its design and coordination. All authors read and approved the final manuscript.

\section{Acknowledgements}

We thank Astrid van der Aa Kühle, Angelika Appold, Katrin Reindl, Jaqueline Müller, Claudia Kloß, Nadine Kink, and Elenore Samson for excellent technical assistance. This work was supported by the Danish Cancer Society, the Novo Nordic Foundation, the Karen Elise Jensen Foundation, the 
Danish Natural Sciences and Medical Research Councils, NIH grant CA 100266, Synergenics LLC, and the National Danish Research Foundation through the Centre for mRNP Biogenesis and Metabolism at the University of Aarhus.

\section{References}

I. Lovmand J, Sørensen AB, Schmidt J, Østergaard M, Luz A, Pedersen FS: B-Cell lymphoma induction by akv murine leukemia viruses harboring one or both copies of the tandem repeat in the U3 enhancer. J Virol 1998, 72(7):5745-5756.

2. Rosenberg $\mathrm{N}$ and P. Jolicoeur: Retroviral pathogenesis . In Retroviruses Edited by: Coffin JMHSHHEV. Cold Spring Harbor Laboratory Press, USA; 1997:475-586.

3. Blair DG, Athanasiou M: Ets and retroviruses - transduction and activation of members of the Ets oncogene family in viral oncogenesis. Oncogene 2000, 19(55):6472-6481.

4. Joosten M, Vankan-Berkhoudt $Y$, Tas M, Lunghi M, Jenniskens $Y$, Parganas E, Valk PJ, Lowenberg B, van den Akker E, Delwel R: Largescale identification of novel potential disease loci in mouse leukemia applying an improved strategy for cloning common virus integration sites. Oncogene 2002, 21 (47):7247-7255.

5. Largaespada DA: Genetic heterogeneity in acute myeloid leukemia: maximizing information flow from MuLV mutagenesis studies. Leukemia 2000, I4(7): I 174-II84.

6. Mikkers H, Berns A: Retroviral insertional mutagenesis: tagging cancer pathways. Adv Cancer Res 2003, 88:53-99.

7. Lenz J, Celander D, Crowther RL, Patarca R, Perkins DW, Haseltine WA: Determination of the leukaemogenicity of a murine retrovirus by sequences within the long terminal repeat. Nature 1984, 308(5958):467-470.

8. Ishimoto A, Adachi A, Sakai K, Matsuyama M: Long terminal repeat of Friend-MCF virus contains the sequence responsible for erythroid leukemia. Virology I985, I4I(I):30-42.

9. Ethelberg S, Sorensen AB, Schmidt J, Luz A, Pedersen FS: An SL3-3 murine leukemia virus enhancer variant more pathogenic than the wild type obtained by assisted molecular evolution in vivo. I Virol I 997, 7 I ( I 2):9796-9799.

10. Lewis AF, Stacy T, Green WR, Taddesse-Heath L, Hartley JW, Speck NA: Core-binding factor influences the disease specificity of Moloney murine leukemia virus. J Virol 1999, 73(7):5535-5547.

II. Sorensen KD, Kunder S, Quintanilla-Martinez L, Sorensen J, Schmidt J, Pedersen FS: Enhancer mutations of Akv murine leukemia virus inhibit the induction of mature B-cell lymphomas and shift disease specificity towards the more differentiated plasma cell stage. Virology 2007, 362(I):|79-19|.

12. Sørensen KD, Sørensen AB, Quintanilla-Martinez L, Kunder S, Schmidt J, Pedersen FS: Distinct roles of enhancer nuclear factor I (NFI) sites in plasmacytoma and osteopetrosis induction by Akv1-99 murine leukemia virus. Virology 2005, 334(2):234-244.

13. Kim JW, Closs El, Albritton LM, Cunningham JM: Transport of cationic amino acids by the mouse ecotropic retrovirus receptor. Nature 1991, 352(6337):725-728.

14. Wang H, Kavanaugh MP, North RA, Kabat D: Cell-surface receptor for ecotropic murine retroviruses is a basic amino-acid transporter. Nature 199|, 352(6337):729-73 |

15. Lander JK, Chesebro B, Fan H: Appearance of mink cell focusinducing recombinants during in vivo infection by moloney murine leukemia virus (M-MuLV) or the Mo+PyFIOI MMuLV enhancer variant: implications for sites of generation and roles in leukemogenesis. J Virol 1999, 73(7):567|-5680.

16. Stoye JP, Moroni C, Coffin JM: Virological events leading to spontaneous AKR thymomas. J Virol I99I, 65(3): I273-1285.

17. Audit M, Dejardin J, Hohl B, Sidobre C, Hope TJ, Mougel M, Sitbon M: Introduction of a cis-acting mutation in the capsid-coding gene of moloney murine leukemia virus extends its leukemogenic properties. J Virol 1999, 73( I 2): 10472-10479.

18. Dejardin J, Bompard-Marechal G, Audit M, Hope TJ, Sitbon M, Mougel $M:$ A novel subgenomic murine leukemia virus RNA transcript results from alternative splicing. J Virol 2000, 74(8):3709-37। 4 .

19. Houzet L, Battini JL, Bernard E, Thibert V, Mougel M: A new retroelement constituted by a natural alternatively spliced RNA of murine replication-competent retroviruses. Embo J 2003, 22(18):4866-4875.
20. Nason-Burchenal K, Wolff L: Activation of c-myb is an early bone-marrow event in a murine model for acute promonocytic leukemia. Proc Natl Acad Sci U S A 1993, 90(4): 1619-1623.

2I. Ramirez JM, Houzet L, Koller R, Bies J, Wolff L, Mougel M: Activation of c-myb by 5 ' retrovirus promoter insertion in myeloid neoplasms is dependent upon an intact alternative splice donor site (SD') in gag. Virology 2004, 330(2):398-407.

22. Morse HC 3rd, Anver MR, Fredrickson TN, Haines DC, Harris AW, Harris NL, Jaffe ES, Kogan SC, MacLennan IC, Pattengale PK, Ward JM: Bethesda proposals for classification of lymphoid neoplasms in mice. Blood 2002, 100(1):246-258.

23. UCSC Genome Bioinformatics [http://genome.ucsc.edu/]

24. Mouse Retrovirus Tagged Cancer Gene Database [http:// rtcgd.abcc.ncifcrf.gov/]

25. Akagi K, Suzuki T, Stephens RM, Jenkins NA, Copeland NG: RTCGD: retroviral tagged cancer gene database. Nucleic Acids Res 2004, 32(Database issue): D523-527.

26. Mikkers H, Allen J, Knipscheer P, Romeijn L, Hart A, Vink E, Berns A: High-throughput retroviral tagging to identify components of specific signaling pathways in cancer. Nat Genet 2002, 32(I): $153-159$

27. Pyrz M, Wang B, Wabl M, Pedersen FS: Identification and analysis of the Invariant chain locus as a common insertion site in retrovirally induced murine lymphomas. Manuscript in prep 2007.

28. Shin MS, Fredrickson TN, Hartley JW, Suzuki T, Agaki K, Morse HC 3rd: High-throughput retroviral tagging for identification of genes involved in initiation and progression of mouse splenic marginal zone lymphomas. Cancer Res 2004, 64( I3):44 I9-4427.

29. Martin-Hernandez J, Balle Sorensen A, Pedersen FS: Non-identical patterns of proviral insertions around host transcription units in lymphomas induced by different strains of murine leukemia virus. Virology 2006, 353(1): 193-199.

30. Ryden TA, Beemon K: Avian retroviral long terminal repeats bind CCAAT/enhancer-binding protein. Mol Cell Biol 1989, 9(3): I I55-II64.

31. Ryden TA, de Mars M, Beemon K: Mutation of the C/EBP binding sites in the Rous sarcoma virus long terminal repeat and gag enhancers. J Virol 1993, 67(5):2862-2870.

32. Erkeland S], Valkhof M, Heijmans-Antonissen C, van Hoven-Beijen A, Delwel R, Hermans MH, Touw IP: Large-scale identification of disease genes involved in acute myeloid leukemia. J Virol 2004, 78(4): $197 \mid-1980$.

33. Lund AH, Turner G, Trubetskoy A, Verhoeven E, Wientjens E, Hulsman D, Russell R, DePinho RA, Lenz J, van Lohuizen M: Genomewide retroviral insertional tagging of genes involved in cancer in Cdkn2a-deficient mice. Nat Genet 2002, 32(1):160-165.

34. Sørensen $A B$, Duch $M$, Amtoft HW, Jørgensen P, Pedersen FS: Sequence tags of provirus integration sites in DNAs of tumors induced by the murine retrovirus SL3-3. J Virol 1996, 70(6):4063-4070.

35. Sørensen KD, Quintanilla-Martinez L, Kunder S, Schmidt J, Pedersen FS: Mutation of all Runx (AMLI/core) sites in the enhancer of T-lymphomagenic SL3-3 murine leukemia virus unmasks a significant potential for myeloid leukemia induction and favors enhancer evolution toward induction of other disease patterns. J Virol 2004, 78(23): |32|6-|323|.

36. Schmidt J, Erfle V, Pedersen FS, Rohmer H, Schetters H, Marquart $\mathrm{KH}$, Luz A: Oncogenic retrovirus from spontaneous murine osteomas. I. Isolation and biological characterization. J Gen Virol 1984, 65(Pt I 2):2237-2248.

37. Kogan SC, Ward JM, Anver MR, Berman JJ, Brayton C, Cardiff RD, Carter JS, de Coronado S, Downing JR, Fredrickson TN, Haines DC, Harris AW, Harris NL, Hiai H, Jaffe ES, MacLennan IC, Pandolfi PP, Pattengale PK, Perkins AS, Simpson RM, Tuttle MS, Wong JF, Morse HC 3rd: Bethesda proposals for classification of nonlymphoid hematopoietic neoplasms in mice. Blood 2002, I00(1):238-245.

38. Van Beveren C Coffin, J., and S. Hughes: Nucleotide sequences complemented with functional and structural analysis. In RNA Tumor Viruses Edited by: Weiss RTHVHJC. New York, CSHL Press; 1985:790-805.

39. Wang CL, Wang BB, Bartha G, Li L, Channa N, Klinger M, Killeen N, Wabl M: Activation of an oncogenic microRNA cistron by provirus integration. Proc Natl Acad Sci U S A 2006, 103(49): 18680-18684. 